\title{
Subscale and Full-Scale Testing of Buckling-Critical Launch Vehicle Shell Structures
}

\author{
Mark W. Hilburger*, Waddy T. Haynie ${ }^{\dagger}$, and Andrew E. Lovejoy ${ }^{\ddagger}$ \\ NASA Langley Research Center, Hampton, Virginia, 23681, USA \\ Michael G. Roberts ${ }^{\S}$ \\ NASA Marshall Space Flight Center, Huntsville, Alabama, 35812, USA \\ Jeffery P. Norris ${ }^{* *}$ \\ Lockheed-Martin Space System Company, Huntsville, Alabama, 35812, USA \\ W. Allen Waters ${ }^{\dagger \dagger}$ and Helen M. Herring \\ Lockheed-Martin Corporation, Hampton, Virginia, 23681, USA
}

\begin{abstract}
New analysis-based shell buckling design factors (aka knockdown factors), along with associated design and analysis technologies, are being developed by NASA for the design of launch vehicle structures. Preliminary design studies indicate that implementation of these new knockdown factors can enable significant reductions in mass and mass-growth in these vehicles and can help mitigate some of NASA's launch vehicle development and performance risks by reducing the reliance on testing, providing high-fidelity estimates of structural performance, reliability, robustness, and enable increased payload capability. However, in order to validate any new analysis-based design data or methods, a series of carefully designed and executed structural tests are required at both the subscale and fullscale level. This paper describes recent buckling test efforts at NASA on two different orthogrid-stiffened metallic cylindrical shell test articles. One of the test articles was an 8-ftdiameter orthogrid-stiffened cylinder and was subjected to an axial compression load. The second test article was a 27.5-ft-diameter Space Shuttle External Tank-derived cylinder and was subjected to combined internal pressure and axial compression.
\end{abstract}

\section{Introduction}

$\mathrm{I}^{\mathrm{n}}$ $\mathrm{n}$ order to achieve improved performance, safety, and reliability, and to reduce the cost and development risks for the next generation of launch vehicles, new structural concepts and materials are needed. In addition, new design technologies must be developed and validated to take full advantage of these new concepts and materials. One such technology development activity at NASA, the Shell Buckling Knockdown Factor Project (SBKF), is tasked with revising the design factors and recommendations for buckling-critical, thin-walled shell structures like those contained in the NASA space vehicle design criteria published back in the late 1960 s and early 1970 s. $^{1-4}$ From approximately 1930 to 1967 , many shell-buckling experiments were conducted, primarily on unstiffened isotropic shells. Typically, the experiments yielded buckling loads that were substantially lower than the corresponding analytical predictions, which were based on simplified linear bifurcation analyses of geometrically perfect shells with nominal dimensions and idealized support conditions. It wasn't until sometime later that it was discovered that small deviations from the idealized geometry of a shell, known as initial geometric imperfections, were a primary

\footnotetext{
${ }^{*}$ Senior Research Engineer, Structural Mechanics and Concepts Branch, Senior Member AIAA.

${ }^{\dagger}$ Research Aerospace Engineer, Structural Mechanics and Concepts Branch, Member AIAA.

${ }^{\ddagger}$ Research Aerospace Engineer, Structural Mechanics and Concepts Branch, Senior Member AIAA.

$\S$ Test Engineer, Structural Strength and Test Branch.

${ }^{* *}$ Senior Manufacturing Engineer, Welding, Design and Fabrication Branch.

${ }^{\dagger}$ Staff Structural Engineer, Structural Mechanics and Concepts Branch, Senior Member AIAA.

\$Senior Research Engineer, Durability and Damage Tolerance Branch.
} 
source of the discrepancy between corresponding analytical predictions and experimental results. However, the computational tools at that time could not perform the computationally intense nonlinear analyses needed assess the effects of these imperfections on the buckling behavior of thin-walled shells. Thus, buckling design allowables were determined by establishing lower bounds to test data.

From the 1960 s to the present, significant improvements in computational tools and testing technologies are enabling the development of analysis-based design methods that will reduce the conservatism in the current design factors, and update them to represent the new structural concepts, manufacturing processes, and materials of modern launch vehicle structures. Thus, a significant part of SBKF is the design and execution of selected subscale and fullscale buckling tests on relevant cylindrical shell test articles. The data obtained from these tests is subsequently used to develop and validate high-fidelity structural models and new analysis-based knockdown factors.

There are two main requirements to be met by the SBKF test program. First, the test article designs and response characteristics must span a specified region of the design space of interest, and certain behavioral characteristics and failure modes must be isolated and studied. For example, orthogrid-stiffened cylindrical structures, such as the ones being studied by SBKF, can exhibit several different failure modes including global buckling, local skin-pocket buckling (i.e., buckling of the thin skin between stiffeners), weld land buckling (buckling of the unstiffened weld region), stiffener buckling, and stiffener crippling. The second requirement is to obtain specific test data needed to validate high-fidelity buckling simulations that will form the basis for the new analysis-based design factors and methods. To meet this requirement, traditional test instrumentation as well as emerging measurement technologies have been implemented into the SBKF test program. To this end, test technology development and verification activities have been conducted to help advance new measurement technologies into standard practice for large-scale structural testing (e.g., 27.5-ft-diameter shells). In particular, large-scale geometry measurement technologies (i.e., metrology) are used routinely after fabrication and prior to testing to determine the as-built geometry of the test article in order to assess its quality and to provide data to model accurately the initial geometry of the test article in high-fidelity buckling simulations. In addition, techniques for using low-speed (1-5 Hz) and high-speed (3 - $15 \mathrm{kHz})$ digital image correlation systems (DIC) on a large-scale test articles have been developed to measure the full-field displacement and strain response of the test articles during testing.

Selected details and results from the SBKF test program are presented in this paper. First, the test article designs and fabrication methods are presented. Then, the test facilities and test methods are described. In particular, subscale and full-scale test facilities and instrumentation are described and include results from large-scale DIC development and verification activities. Finally, selected results from recent buckling tests on two different orthogrid-stiffened metallic cylindrical shells are presented including results from a compression test on an 8-ft-diameter test article and results from a 27.5-ft-diameter Space Shuttle External Tank-derived test article subjected to combined internal pressure and axial compression.

\section{Test Article Design and Fabrication}

The design and fabrication of a typical subscale 8-ft-diameter orthogrid-stiffened cylinder, TA01, and a typical full-scale 27.5-ft-diameter orthogrid-stiffened cylinder, ETTA1, are presented in this section. In addition, the quality of these cylinders is established by conducting detailed post-fabrication geometry measurements and the results of these measurements are discussed herein.

\section{A. Subscale Cylinder TA01}

TA01 is an 8-ft-diameter cylinder test article designed to meet two specific test requirements. First, test results were needed to validate the test-article design and analysis approach, and to verify the performance of a new purpose-built test frame used for the test program (to be described in a later section). Second, the test-article construction and test data should be relevant for the design of modern orthogrid-stiffened metallic launch vehicle structures currently being considered by NASA. To meet these requirements, a lightly stiffened design was developed for TA01 and is summarized in Table 1. The orthogrid stiffener pattern and design variables are shown in Fig. 1, where $t$ is the skin thickness, $t_{s}$ is the stringer thickness, $t_{r}$ is the ring thickness, $h$ is the stiffener (stringer and ring) height, $H$ is the total orthogrid height, $b_{s}$ is the stringer spacing, and $b_{r}$ is the ring spacing. Finally, the effective shell wall thickness $t_{e f f}$, often used to characterize the thickness of a stiffened skin (e.g., Ref. 1), is reported in the table and is given by 


$$
t_{\text {eff }}=\sqrt[4]{\frac{144 D_{11} D_{22}}{A_{11} A_{22}}}
$$

where $D_{11}$ and $D_{22}$ are the bending stiffnesses in the axial and circumferential directions, respectively, and $A_{11}$ and $A_{22}$ are the membrane stiffnesses in the axial and the circumferential directions, respectively. The test article was designed to exhibit a relatively simple and predictable global buckling response as the primary failure mode, and included large margins for material yielding and skin and stiffener buckling in order to reduce the potential for failure mode coupling. The skin is relatively thick at 0.100 in. to prevent skin pocket buckling, and the stiffeners were chosen to be short with a small height-to-thickness ratio, $h / t_{s}$ of 3 , to prevent stiffener buckling and crippling. The test article was designed to be constructed from three, 120-degree arc-length, orthogrid-stiffened curved panel segments that were welded together along three longitudinal weld lands to form a circular cylinder. The three stiffened curved panel segments were fabricated by first machining the orthogrid stiffener pattern into a flat sheet of material; the flat sheet was then bump-formed to the desired curvature and heat treated to remove residual stresses from the panel. The welding was performed on a vertical friction-stir-welding tool. Once the cylinder was fabricated, the ends, also referred to as loading surfaces, were machined to specific tolerances necessary to provide uniform load introduction during testing. In particular, machining tolerances were specified for flatness of the loading surfaces, parallelism between the top and bottom loading surfaces, and perpendicularity of the axis of the cylinder relative to the plane of the loading surfaces. All these tolerances were subsequently verified after machining. After machining was complete and tolerances were verified, both ends of the cylinder were potted into single-piece interface rings. The low-melting-point alloy Cerrobend-158 was used for the potting material. The interface rings are used to attach the cylinder test article to the test frame. Similar machining tolerances were specified in the fabrication of the interface rings and were verified before use. A typical 8- $\mathrm{ft}$ diameter orthogridstiffened friction-stir welded cylinder is shown Fig. 2. One of the three longitudinal weld lands is indicated in the figure and a portion of the stiffener pattern is marked with a set of longitudinal and circumferential grid lines. Additional details on the design of TA01 along with other 8-ft-diameter cylinder test articles are contained in Refs. 5-7.

Table 1. Acreage Design for TA01.

\begin{tabular}{cc}
\hline Orthogrid Variable & Value \\
\hline$t$ (in.) & 0.100 \\
$H$ (in.) & 0.400 \\
$h$ (in.) & 0.300 \\
$b_{S}$ (in.) & 4.00 \\
$t_{S}$ (in.) & 0.100 \\
$b_{r}$ (in.) & 4.00 \\
$t_{r}$ (in.) & 0.100 \\
$R / t_{\text {eff }}$ & 230.9 \\
\hline
\end{tabular}

After TA01 was potted in the interface rings, the as-built geometry of its outer surface was measured and is shown in Fig. 3. The coordinate system used to display this data is defined in Fig. 4. The geometry was measured by using the TriTop photogrammetry system and the ATOS III-S white light scanner system both manufactured by GOM mbH. The geometry measurement utilizes a two-part approach. First, global geometry data from the cylinder's outer surface is obtained with the photogrammetry system and serves as a three-dimensional framework of surface points onto which local high-fidelity geometry measurements are added. The high fidelity geometry measurements are obtained by using the white light scanner system. The blue and red colored contours correspond to inward and outward radial imperfections (deviations from the perfect circular cylinder), respectively, and the vertical dashed lines indicate the location of the three longitudinal weld lands. The measured imperfection exhibits a small amplitude $(<0.1 \mathrm{in}$.) short-wave-length periodic variation around the circumference and slight variation along its length. The weld land features do not appear to affect the as-built geometry significantly. 


\section{B. Full-Scale Cylinder ETTA1}

ETTA1 is a full-scale 27.5-ft-diameter cylinder test article designed to meet several test requirements. First, test data was needed to verify that the data obtained from the analysis and testing of subscale 8-ft-diameter test articles, such as TA01, scale up to full-scale vehicle structures and would be relevant for design. Second, geometric imperfection measurements of as-built full-scale hardware were needed to verify assumptions on imperfection shapes and amplitudes used to develop future analysis-based knockdown factors. Third, test results were needed to validate finite-element model predictions of complex buckling phenomena in launch-vehicle-like buckling-critical cylinders. To this end, ETTA1 was designed and fabricated from excess Space Shuttle External Tank (ET) hardware. This cylinder was constructed from eight integrally-machined orthogrid-stiffened panels that were friction-stir-welded together along longitudinal weld lands to form a complete cylinder. ETTA1 is shown at the vertical weld facility at NASA's Marshall Space Flight Center in Fig. 5. The entire manufacturing process was very similar to that of TA01 as described in the previous section. The acreage design for ETTA1 is summarized in Table 2. The actual test-article acreage geometry differs slightly from the geometry reported here. In particular, many areas of the cylinder are tailored for specific ET flight load conditions however the exact dimensions of these tailored regions are not disclosed herein. After the cylinder was welded together, cylinder-end machining, machining tolerance verification, and interface ring installation was conducted. In addition, the as-built geometry of the ETTA1 outer surface was measured and is shown in Fig. 6. The blue and red colored contours in Fig. 6 correspond to inward and outward radial imperfections and the dashed vertical lines indicate the locations of the longitudinal weld lands. In this case, the measured geometry data indicates a significant geometry variation near the weld lands and is in marked contrast to the data presented for TA01. It is unknown what causes these local distortions to be more prominent in ETTA1 as compared to TA01, however, measured geometry data from several different cylinder designs suggest that stiffener design details adjacent to the weld land and local curvature of the cylinder may play a role. Additional details on the design of ETTA1 are contained in Ref. 7.

Table 2. Acreage design used in ETTA1.

\begin{tabular}{cc}
\hline Orthogrid Variable & Value \\
\hline$t$ (in.) & 0.09 \\
$H$ (in.) & 1.05 \\
$h$ (in.) & 0.96 \\
$b_{s}$ (in.) & 10.8 \\
$t_{S}$ (in.) & 0.09 \\
$b_{r}$ (in.) & 15.32 \\
$t_{r}$ (in.) & 0.10 \\
$R / t_{\text {eff }}$ & 326.4 \\
\hline
\end{tabular}

\section{Test Facilities and Instrumentation}

Facilities and instrumentation used in the SBKF buckling tests of subscale 8-ft-diameter and full-scale 27.5-ftdiameter cylinders are described in this section. In addition, results from the development and verification of digital image correlation measurements techniques on large-scale structures are presented. Additional details on the process of developing test facilities and test instrumentation requirements can be found in Ref. 8 .

\section{A. Subscale and Full-Scale Test Facilities}

\section{Subscale test facility}

A shell buckling test facility was developed by SBKF for testing 8-ft-diameter cylinders subjected to combined axial compression, bending, and internal pressure, and is shown in Fig. 7. This facility is comprised of the test frame (shown in the figure), MTS FlexTest 60 multi-channel load control system (LCS), custom-built 1000-channel data acquisition system, six synchronized Correlated Solutions digital image correlation systems used for measuring full- 
field displacements and strains on the outer surface of the cylinder, and six Image Research Phantom 7.1 high-speed digital video cameras used to record any dynamic buckling or failure events.

The self-reacting test frame is comprised of two loading spiders, struts, two load introduction cylinders, and eight load lines. Each of the load lines are comprised of a hydraulic actuator, a 4-in-diameter loading rod, and a load cell and connect the upper and lower loading spiders. The 8-ft-diameter test article is attached between the upper and lower load introduction cylinders via single-piece interface rings and the load is applied to the cylinder by extending and contracting the hydraulic actuators in the load lines. The test frame can apply a maximum compression load of 1.8 million $\mathrm{lb}$ and an internal pressure load of $10 \mathrm{psi}$. Each of the components of the test frame were designed and analytically verified to ensure uniform loading into the test article. Different length cylinder test articles can be accommodated in the test frame by changing the lengths of loading rods in the load lines.

The shell buckling tests considered here utilize multiple load lines which are controlled by a multi-channel LCS with primary, secondary feedback data obtained from the load cells and electronic displacement indicators (EDI's) that are incorporated in each load line (see Fig. 7). Each actuator can be controlled independently by the LCS by prescribing a desired load rate or displacement rate depending on the desired load sequence and enables the testing of cylinders in various combinations of compression and bending. In addition, upper and lower error bounds on the primary actuator load data and secondary actuator displacement control signals can be prescribed. If the error bounds are exceeded by the as-measured data during the test, then the LCS is programmed to automatically go into a position or displacement hold at which time a judgment is made as to whether the test should proceed or be terminated.

Six low-speed digital image correlation systems and six high-speed digital cameras are positioned around the circumference of the test article to record the static and dynamic displacement response of the cylinder wall during testing. Digital image correlation (DIC, photogrammetry) is an optical displacement and strain measurement technique initially developed by a group of researchers located at the University of South Carolina with the support from NASA Langley Research Center. The technique uses a proprietary mathematical correlation method to analyze digital image data taken of a high-contrast speckle pattern on the surface of the test article (e.g., see TA01 in Fig. 7) while a test specimen is subjected to load. Consecutive digital images taken during a test are used to monitor changes in the speckle pattern as the specimen is loaded and can determine very accurately the full-field displacements and strains of high-contrast speckle patterns in the images. The current low-speed DIC systems use 5-megapixel camera pairs positioned around the circumference of the test article to obtain full viewing coverage of the test article outer surface. The high-speed cameras are also positioned around the circumference and are typically programmed to take images at $4000 \mathrm{~Hz}$ with a resolution of $400 \times 600$ pixels. Higher frame rates can be used at reduced resolutions as required.

\section{Full-scale test facility}

A similar shell buckling test facility was developed by SBKF for testing 27.5 -ft-diameter cylinders subjected to combined axial compression, bending, and internal pressure, and is shown in Fig. 8. This facility is comprised of upper and lower load introduction cylinders and load lines (shown in the figure), MTS FlexTest 200 multi-channel LCS, custom-built 1000-channel data acquisition system, eight synchronized Correlated Solutions DIC systems, and six Image Research Phantom 7.1 high-speed digital video cameras.

The upper and lower load introduction cylinders are constructed from aluminum hat-stiffened cylinders (brown colored structures) with large steel end rings (white colored structures). These cylinders were originally fabricated for the Space Shuttle External Tank (ET) structural qualification testing in the 1970's and were designed to exhibit similar stiffness characteristics found in the ET so that flight-like boundary conditions and loads could be simulated accurately, e.g., flight-like interface stiffnesses and load paths and attachment geometry. The 27.5 -ft-diameter test article is attached between the upper and lower load introduction cylinders via test article interface rings and the load is applied to the cylinder by extending and contracting the hydraulic actuators in the load lines that react off of the upper crosshead. This particular test configuration shown in Fig. 8 uses eight load lines to apply up to 2.0 million $\mathrm{lb}$ of compression load; however, the loading capacity can be increased by adding additional load lines. The crosshead can move vertically to a maximum height of $120 \mathrm{ft}$. and can react up to 10 million $\mathrm{lb}$ of compression or tension loads. In addition, the upper and lower load introduction cylinders were modified to enable an internal pressure loading of $1.5 \mathrm{psi}$. A load control system, similar to the one used in the subscale test facility, is used to control each load line independently either in load control or displacement control and enables the testing of cylinders in various combinations of compression and bending. Six low-speed digital image correlation systems and six high-speed digital cameras are positioned around the circumference of the test article to record both static and dynamic displacement response of the cylinder wall during testing. In addition, two internal DIC systems are used to 
measure local displacement response of the stiffeners, skin, and weld lands and the resolution of these measurements is approximately proportional to the measurement field of view (i.e., the physical dimensions of the measurement area). The high-speed cameras are also positioned around the circumference and are programmed to take images at $3000 \mathrm{~Hz}$ with a resolution of $600 \times 800$ pixels. Additional details on typical test article instrumentation and DIC configurations are presented in the following sections.

\section{B. Instrumentation}

Several types of instrumentation are employed to obtain data from the subscale and full-scale tests in order to meet specific test data requirements. In particular, test data is required to monitor the performance of the test frame and load introduction into the test article during the test. Similarly, data is required to validate high-fidelity computer simulations of the pre-buckling, buckling, and post-buckling behavior of the test article, including the internal load distribution and displacement response. Typical types of instrumentation that are used to meet these data requirements are presented for TA01 and ETTA1 in this section.

The test article boundary conditions and load introduction are assessed primarily by using a combination of strain gages and electronic displacement indicators (EDI's). The relative displacements of the top and bottom test article interface rings are measured at several locations. For example, axial displacement measurements are taken at eight locations as shown in Fig. 9a, and are used to characterize the end-shortening displacements and bending displacements. Similarly, transverse displacement measurements are made at several locations, as shown in Fig. 9b, and are used to determine any resulting translational and torsional displacements during the test. Additional displacement measurements are taken on the full-scale test articles, such as ETTA1, in order to characterize local rotations at the test-article-to-load-introduction-cylinder interface, as shown in Fig. 9c. In this case, preliminary analysis results and measured data from back-to-back strain gages on the load introduction cylinders indicated the potential for significant local bending at the interface (see a typical back-to-back interface strain gage arrangement in Fig. 9c). Thus, additional EDI's were positioned at eight locations on the full-scale test setup to characterize these rotations (measurement locations correspond to locations shown in Fig. 9a). From these local strain measurements and interface rotation measurements, the effective interface stiffness can be determined and compared to the predicted stiffness. The load introduction into the test articles is characterized by strain gages positioned every $22.5-$ degrees around the circumference of the load introduction cylinders near the test-article-to-load-introductioncylinder interface. In addition, back-to-back strain gages are positioned at several circumferential locations near the loaded ends of the test article on the test article skin, stiffeners, and weld lands, as illustrated in Fig. 10 for one of the eight curved panel sections from ETTA1. These back-to-back strain gages are critical in characterizing the as-tested loads in the test article during the test and help determine the load sharing between the different components of these stiffened structures. The DIC systems were typically used to provide a qualitative assessment of the load introduction into the test articles due to the limitations on resolution and were mainly used to verify that no anomalous behavior was occurring in areas of the test article that were not instrumented.

The pre-buckling, buckling, and post-buckling internal load distribution and displacement responses were characterized by a combination of strain gages, EDI's, and DIC full-field displacement measurements. Selected skin pockets, stiffeners, and all weld lands were instrumented with back-to-back strain gages at several circumferential locations and five different axial location along the length of the cylinders, as shown in Fig. 10, in order to characterize local structural behavior such as skin and stiffener buckling and the associated strain redistribution that could not be measured effectively by the DIC systems. The subscale test articles, such as TA01, typically have a total of 300-400 strain gages and EDI's, and the full-scale test articles, such as ETTA1, have 800-900 strain gages and EDI's. The DIC systems were the primary means of obtaining full-field shell-wall displacements; however, EDI's were also used to verify the DIC radial displacement measurements in select locations. Some of the typical DIC system requirements and set up details are discussed in the next section.

\section{Digital Image Correlation for Subscale and Full-Scale Cylinder Tests}

The DIC systems are used to meet several displacement measurement requirements. First, the DIC systems are required to measure synchronized full-field buckling displacements including local pocket buckling and global weld land and acreage buckling. Second, the DIC systems are required to measure quasi-static and transient-dynamic displacement responses. The quasi-static displacement measurements are obtained by using three-dimensional DIC systems that consist of low-speed 5-megapixel camera pairs taking images at 1-2Hz. The transient-dynamic buckling displacement responses are obtained by using two-dimensional high-speed DIC systems that consist of 
high-speed camera taking images at 3-4kHz and resolutions between 0.25-0.5 megapixels. However, one of the main challenges in meeting the measurement requirements for both systems is to determine a common speckle pattern size that both the high-resolution low-speed cameras and the lower-resolution high-speed cameras could use and still provide the required spatial resolution, measurement accuracy, and high-speed camera frame rate. For the subscale and full-scale testing considered herein, it was determined that some of the original low-speed and highspeed DIC measurement requirements could not be mutually satisfied because of the camera resolution mismatch and, thus, it was necessary to make a compromise. It was decided that an emphasis would put on obtaining accurate low-speed DIC measurements, which were deemed more critical to the successful validation of the high-fidelity cylinder buckling simulations than the high-speed data. This resulted in a speckle pattern size that reduced the accuracy of the high-speed DIC measurements.

A typical top view of a DIC configuration is shown for the full-scale shell buckling test facility in Fig. 11. The figure shows the cross-section of the 27.5-ft-diameter test article and the internal and external low-speed DIC camera systems. The camera system locations are marked with red squares and their viewing areas are indicated by the blue shaded triangles. The external cameras are located between $15 \mathrm{ft}$. and $45 \mathrm{ft}$. away from the outer surface of the test article (this distance is also referred to as the camera stand-off distance) and $20 \mathrm{ft}$. to $45 \mathrm{ft}$. off the floor of the test facility and are mounted on the existing test facility structure. The physical locations of the cameras can present several challenges to the DIC operators associated with DIC system configuration, refinement, calibration, and measurement verification because much of the adjustments need to be performed to the camera. Thus, much of the DIC system development and verification for the full-scale test facility was conducted through careful ground testing before final implementation. For example, a detailed system development and verification study was conducted prior to ETTA1 testing. The objective of this study was to determine the speckle pattern dimensions, camera parameters (e.g., camera stereo angle, lens size, depth-of-field) and calibration routines necessary to obtain the required displacement measurements. To this end, two ground-based test simulators were developed and are shown in Fig. 12. The first simulator was designed to mimic the expected local skin pocket buckling of ETTA1 with out-of-plane displacements ranging from -0.25 in. to 0.15 in. This simulator was constructed from a 4-ft. by 8 -ft. flat panel with four 8-in. by 12-in. rectangular plastic panel sections that could be displaced out of the plane of the panel a known distance and to simulate the steep displacement gradient that is expected to occur between buckled pockets. Typical measured out-of-plane skin buckling displacements, $\mathbf{W}_{\mathbf{1}}$, are shown in Fig. 12 and indicated that the DIC system would be able to successfully measure the local buckling response in the cylinder with a resolution of approximately $0.04 \mathrm{in}$. and an accuracy of $\pm 0.01 \mathrm{in}$. The second simulator was used to determine the resolution and accuracy of global out-of-plane displacement measurements and is constructed from a 4-ft. by 8 -ft. flat panel and was attached to a rigid frame with a set of hinges. The panel can be pivoted out of plane a known distance at the base of the panel to produce a shallow displacement gradient that would be observed in the global buckling of a large-diameter cylinder. Typical measured out-of-plane skin buckling displacements, $\mathbf{W}_{\mathbf{2}}$, are shown for a panel edge displacement of 3.0 in., the maximum expected global buckling displacements for ETTA1. The results from the global displacement simulator indicated a resolution of $0.07 \mathrm{in}$. and an accuracy $\pm 0.01 \mathrm{in}$. The difference in the measurement resolution for the local and global displacements is attributed to the fact that the mathematical correlation methods typically resolve steep displacement gradients, such as those in the local buckling test, better than shallow gradients such as that exhibited by the global displacement test. However, the accuracy is the same for local and global displacement tests and is dictated primarily by the inherent noise in the DIC system. Overall, the results from this DIC development and verification study were very useful in refining the configuration specifications for the full-scale test facility and indicated that proper set-up of the camera systems would enable displacement measurements that would meet or exceed the required measurement resolution and accuracy necessary for validating high-fidelity buckling simulations.

\section{Test Results}

Selected results from a subscale 8-ft-diameter test article, TA01, subjected to an axial compression load and a full-scale 27.5-ft-diameter test article, ETTA1, subjected to combined internal pressure and axial compression, are presented in this section. In particular, results will be presented to describe the typical behavior of these bucklingcritical cylinders, illustrate the types of data that are used to verify the quality of the test as well as validate highfidelity simulations of cylinder buckling. To this end, the data presented includes measured load versus enddisplacement and load versus end-rotation response curves, full-field axial and radial displacement contours, and selected local strain gage measurements. 


\section{A. TA01 subjected to axial compression}

Results from the buckling test of TA01 subjected to an axial compression load are presented in this section. First, the pre-buckling, buckling and post-buckling behavior of the cylinder is described. Then selected results are presented and are used to illustrate the as-tested or actual loading conditions for TA01.

The measured load-end-shortening response curve for TA01 is shown in Fig.13. The axial load P is normalized by the predicted linear bifurcation buckling load for an idealized, geometrically perfect cylinder $\mathrm{P}_{\mathrm{cr}}=726,800 \mathrm{lb}$. Selected points $\mathbf{a}, \mathbf{b}$, and $\mathbf{c}$ are identified on the curve and correspond to DIC displacement results shown in Figs. 14,15 , and 16, respectively. The results indicate that TA01 exhibits a linear pre-buckling response up to a limit load $\mathrm{P} / \mathrm{P}_{\mathrm{cr}}=0.95$. Typical pre-buckling radial displacement contours are shown in Fig. 14, corresponding to point $\mathbf{a}$ in Fig. 13 at a load of $\mathrm{P} / \mathrm{P}_{\mathrm{cr}}=0.55$, and indicate the formation of several dimples near the mid-length of the cylinder, e.g., at $\theta=130^{\circ}$ and between $230^{\circ}$ and $280^{\circ}$. As loading is increased up to the limit load at point $\mathbf{b}$ in Fig. 13, a single dimple at $\theta=260^{\circ}$ becomes dominant, as shown in Fig. 15, and initiates the global buckling of the cylinder. Upon global buckling, the cylinder exhibits a significant reduction in the axial load to $\mathrm{P} / \mathrm{P}_{\text {cr }}=0.38$ and largemagnitude radial displacements form in the cylinder wall as shown in Fig. 16. The magnitude of the inward radial displacements are 10-15\% larger near the weld lands located at $\theta=-60^{\circ}, 60^{\circ}, 180^{\circ}$. In addition, the post-buckling displacement response is not symmetric and is attributed to a combination of non-uniform load redistribution and material yielding that occurred in the cylinder during the buckling event.

The load introduction into the test article is verified by using a combination of strain measurements and EDI's as described in Section III-B. Typical measured axial membrane strains from 18 locations around the circumference of the cylinder are shown in Fig. 17 (indicated by filled black circle symbols) and correspond to a pre-buckling load level of $\mathrm{P} / \mathrm{P}_{\mathrm{cr}}=0.4$. Maximum compression strains occur at each of the three longitudinal weld lands $\left(\theta=-60^{\circ}, 60^{\circ}\right.$, $180^{\circ}$ ) and range from -615 to -635 microstrain, corresponding to a variation of $\pm 1.6 \%$. Similarly, minimum compression strains occur near the mid-width of each curved panel section of the cylinder $\left(\theta=0^{\circ}, 120^{\circ}, 240^{\circ}\right)$ and range from -498 to -510 , corresponding to variation of $\pm 1.2 \%$. These strain results indicate an overall symmetric loading of the cylinder. Measured load versus torsional rotations and load versus bending rotations of the upper test article interface ring are shown in Figs. 18 and 19, respectively. It is important to note that these measurements are intended to be global rigid-body measurements taken at the interface ring and do not account for local deformations in the interface ring itself which are assumed to very small. The maximum bending rotations are less than $1 \%$ of the predicted critical bending buckling rotations and the maximum torsional rotations are approximately $2 \%$ of the predicted critical torsional buckling rotations. Similarly, measured load versus transverse displacements of the upper test article interface ring are shown in Fig. 20. The maximum transverse displacement is approximately 4\% of the predicted critical transverse buckling displacement. During the buckling event, the end-shortening of TA01 increased suddenly from $0.12 \mathrm{in}$. at the limit load at point $\mathbf{b}$ to $0.2 \mathrm{in}$. at the initial post-buckling configuration at point c, as shown in Fig. 13. This sudden increase in end-shortening is attributed a release of strain-energy throughout the test frame that occurs when the cylinder buckles and loses axial stiffness. When the strain energy in the test frame is reduced, the test frame structure itself (e.g., load lines, load introduction cylinders, etc.) elongates and imparts additional end-shortening onto the cylinder. In addition, other data indicates similar sudden changes in the measured boundary displacements such as the bending rotations shown in Fig. 19 and the transverse displacements shown in Fig. 20. Of particular interest is the fact that the resulting bending rotations in Fig. 19 indicate a rotation of the top test article interface ring towards the circumferential location of the cylinder in which global buckling initiated. Overall, the measured results presented here helped to verify that the test article was loaded uniformly up to buckling or limit load and that only slight variations in load were observed. In addition, the results from the test met the test objective to obtain data for the global buckling of an orthogrid-stiffened, compression-loaded subscale launch vehicle cylinder.

\section{B. ETTA1 subjected to combined internal pressure and axial compression}

Selected results from the installation and subsequent tests of ETTA1 subjected to combined internal pressure and axial compression loads are presented in this section. First, data obtained during the installation of the test article into the test frame and from a preliminary sub-critical load checkout test are presented and used to describe some of the adjustments that were made to the test set-up in order to achieve a uniform applied load. Then, the pre-buckling, buckling and post-buckling behavior of the cylinder subjected to a combined internal pressure and axial compression is described. Finally, selected results are presented to illustrate the as-tested loading conditions for ETTA1. 
It was determined in the preliminary analysis of the ETTA1 test article that the response would be very sensitive to non-uniform loading. In particular, analysis results predicted critical buckling strains on the order of -600 microstrain and a corresponding end-shortening of 0.144 in. $^{7}$ Thus, it was expected that any small deviation or mismatch between the interface ring geometry and the load introduction cylinder could cause a local load concentration and premature buckling to occur in the cylinder. In addition, the integration of the cylinder test article into the test frame required lifting the test article $30 \mathrm{ft}$ vertically over the lower load introduction cylinder and then carefully lowering the test article into position (see Fig. 8 for reference). It was likely that, during this installation process, the test article would initially contact only a portion of the lower load introduction cylinder as it was lowered into its final position and thus might result in a local overloading of the test article. A similar scenario was also likely to occur when the 80,000-lb upper load introduction cylinder was lowered into position on top of the test article. Thus, data from 144 strain gages spaced every 5-deg. around the circumference of the test article (72 near the top edge and 72 near the bottom edge, see Fig. 10) along with back-to-back strain gages from the load introduction cylinders (see Fig. 9) were monitored during the entire installation process to verify that no significant load excursions occurred in the test article. Once the test article was in place, the uniformity of the load introduction into the test article assessed by applying an $80,000 \mathrm{lb}$ dead weight of the upper load introduction cylinder onto the test article and monitoring the same axial strain gages near the test article interface and on the load introduction cylinders. Typical strains from 72 axial strain gages at the top of the test article are shown in Fig. 21a and indicate a significant variation in the strain distribution on the order of $\pm 12 \%$ of the critical buckling strain. It was hoped that a maximum strain variation of $\pm 5 \%$ of the critical buckling strain could be achieved by applying shims between the test article interface ring and the load introduction as illustrated in Fig. 9c. After several loading cycles and shimming applications, the load distribution into the test article was improved significantly as indicated by the strain data shown in Fig. 21b. This post-shimming strain data shows an average strain of approximately $-60 \pm 20$ microstrain and corresponds to a variation of approximately $\pm 3 \%$ of the critical buckling strain. The load introduction is verified further by conducting a sub-critical load test in which an axial load of $45 \%$ of the critical buckling load is applied to the test article and strain and displacement data is monitored. Measured axial membrane strains from 32 circumferential locations around the cylinder are shown in Fig. 22 (indicated by filled black circle symbols) and correspond to an axial load level of $\mathrm{P} / \mathrm{P}_{\mathrm{cr}}=0.45$, where $\mathrm{P}_{\mathrm{cr}}=770,000 \mathrm{lb}$. Minimum compression strains typically occur at each of the eight longitudinal weld lands and are marked with a red ring around the data point and range from -224 to -242 microstrain, corresponding to a variation of $\pm 3.9 \%$. Similarly, maximum compression strains occur near the mid-width of each curved panel section of the cylinder and range from -265 to -295 , corresponding to variation of $\pm 5.3 \%$. These strain results indicate an overall symmetric loading of the cylinder. However, many of the back-to-back strain gage pairs on the upper and lower load introduction cylinders (see Fig. $9 \mathrm{c})$ indicated that a significant amount of bending was occurring at the interface with the test article as shown in Fig. 23. Thus, additional EDI's were placed at eight locations on the upper and lower load introduction cylinder to characterize the rotations of the interface, as illustrated in Fig. 9c. The sub-critical load test was then repeated and results from one of the interface rotation measurements are shown in Fig. 24. The results indicate that the bottom interface is rotating as much as 0.1 -degrees. In contrast the upper interface is much stiffer due to the fact its skin in the interface region is approximately $67 \%$ thicker than the lower interface. These additional EDI's would be used for the remainder of the testing in order to characterize the interface response and would provide critical data necessary to validate subsequent high-fidelity simulations of the ETTA1 test article.

The measured load-end-shortening response curve for ETTA1 subjected to internal pressure and axial compression is shown in Fig. 25. Two different curves are displayed and include results for an internal pressure load of $1.0 \mathrm{psi}$ and $0.6 \mathrm{psi}$, indicated by the gray and black lines, respectively. The axial load $\mathrm{P}$ is normalized by the predicted linear bifurcation buckling load for an idealized geometrically perfect cylinder $P_{c r}=770,000 \mathrm{lb}$. Selected points a through $\mathbf{e}$ are identified on the curve and correspond to DIC displacement results shown in Figs. 26 through 30. First, ETTA1 is pressurized to an internal pressure of 1psi while maintaining zero axial load. The measured radial displacements and axial displacements associated with the initial pressurization are show in Figure 26a and $26 \mathrm{~b}$, respectively, and correspond to point $\mathbf{a}$ on the load-end-shortening curve in Fig. 25. The radial displacements are normalized by $t_{\text {eff }}=0.51 \mathrm{in}$. and the axial displacement $\mathbf{u}$ is normalized by the cylinder length $\mathbf{L}=240 \mathrm{in}$. The radial displacement contours indicate an outward bulging of the cylinder wall near the weld lands and slight inward deformation of each panel in between the welds. In addition, normalized $\mathbf{u}$ displacement contours indicate an extension of the cylinder near each of the weld lands. Once the test article is pressurized to 1psi, axial load is then applied. The load - end-shortening response curve in Fig. 25 indicates a linear response up to a load level of approximately $\mathrm{P} / \mathrm{P}_{\mathrm{cr}}=0.65$, corresponding to point $\mathbf{b}$ on the curve. At point $\mathbf{b}$, the test article begins to exhibit local skin pocket buckling and the weld lands appear to deform radially inward as shown in Fig. 27a. In addition, the u- 
displacement contours indicate that the end displacements are not uniform. This non-uniform end-shortening is attributed to the fact that the weld lands have relatively high membrane stiffnesses that are on the order of the membrane stiffnesses of the load introduction cylinders near the attachment flange (see Fig. 9c) and cause the interface between the test article and load introduction cylinder to deform. As additional axial load is applied to the test article the skin continues to buckle as shown in Fig. 28a and the non-uniformities in end-shortening displacements appear to become less distinct as shown in Fig. 28b. The gradual accumulation of buckled skin cause the effective axial stiffness of the test article to decrease as indicated by the reduction in slope from point $\mathbf{b}$ to point $\mathbf{c}$ on the load--end-shortening curve in Fig. 25. At point $\mathbf{c}$, corresponding to a load level of $\mathrm{P} / \mathrm{P}_{\mathrm{cr}}=1.04$, the data from the test (not presented here) appeared to indicate that the test article was going to buckle at a load level much higher than was expected. Due to safety concerns associated with the possibility of rupturing a pressurize test article, it was decided that the internal pressure should be reduced before the test could be continued. Thus, the test article was first unloaded down to a load level of $\mathrm{P} / \mathrm{P}_{\mathrm{cr}}=0.80$ and then the internal pressure was slowly reduced to $0.6 \mathrm{psi}$ to point C'. The load-end-shortening response curve associated with an internal pressure of 0.6psi is shown in black. Loading from point $\mathbf{c}$ ' to point $\mathbf{d}$ results in similar local pocket buckling behavior as shown in Fig. 28a. Point $\mathbf{d}$ correspond to buckling of the weld land at $-22.5^{\circ}$ as shown in Fig. 29a at a load level of $\mathrm{P} / \mathrm{P}_{\mathrm{cr}}=0.97$. The axial displacement contours shown in Fig. 29b do not indicate any effect of the buckling on the end-shortening displacements. As additional axial end-shortening is applied to the test article, progressive buckling of the remaining weld lands occurs, as shown in Fig. 30a, and corresponds to a reduction in the overall load carrying capability of the test article as indicated by the incremental reduction in load from point $\mathbf{d}$ to point $\mathbf{e}$ on the load-end-shortening curve in Fig. 25. In addition, the axial displacement contours in Fig. 30b indicate a significant variation in the endshortening displacements once buckling occurs. Beyond point $\mathbf{e}$, additional end-shortening was applied to the test article and additional buckles formed in the test article acreage between the weld lands until the termination of the test at an end-shortening value of approximately 0.3 in at which time wide-spread material yielding and stiffener failures were observed.

The load introduction into the test article was characterized by using a combination of strain measurements and EDI's as described in Section III-B. Measured load versus bending rotations and load versus transverse displacements of the upper test article interface ring are shown in Figs. 31 and 32, respectively. It should be noted that some of the results in Figs. 31 and 32 exhibit a distinct discontinuity in the data at $\mathrm{P} / \mathrm{P}_{\mathrm{cr}}=0.5$ and corresponds to a preprogrammed change in the LCS from load control to displacement control. This loading approach is often used in SBKF testing so that any local buckling global buckling events at higher load levels that cause a sudden drop in load or sudden loss of test article stiffness would not results in an unstable load control scenario. The maximum bending rotations shown in Fig. 31 are approximately $5 \%$ of the predicted critical bending buckling rotations of 0.00015 -deg and the maximum transverse displacements are approximately $1.8 \%$ of the predicted critical transverse displacement of $0.282 \mathrm{in}$. Typical rotation measurements made at the upper and lower test article interface are shown in Fig. 33. The results indicate a linear rotation response of the lower interface with a maximum rotation of 0.89-deg. The stiffer upper interface exhibits a maximum rotation of 0.18-deg. Overall, the measured results presented here helped to verify that the test article was loaded uniformly up to buckling and that only slight variations in load were observed.

\section{Concluding Remarks}

The testing of two different buckling-critical orthogrid-stiffened aluminum test article is described in the present paper. The test articles were designed to meet several different test requirements and included behaviors such as global buckling, local skin buckling and longitudinal weld-land buckling. The test methods and instrumentation were discussed, and selected results were presented to illustrate the measured response of each cylinder test article. In addition, some of the requirements associated with developing and performing the tests were described and design solutions were provided. The first test article, TA01, was designed to exhibit global buckling and was used to validate the test-article design process and to serve as a checkout test article in a new purpose-built buckling test facility at NASA. The second test article, ETTA1, was a full-scale 27.5.ft-diameter Space Shuttle External-Tankderived test article subjected to combined internal pressure and axial compression and exhibited a complex buckling behavior. In addition, the results from ETTA1 indicate the importance of installing proper instrumentation to characterize the boundary conditions and load introduction into these types of thin-wall buckling critical test articles. 


\section{Acknowledgments}

This work was conducted as part of the NASA Engineering and Safety Center (NESC) Shell Buckling Knockdown Factor Project, NESC Assessment \#:07-010-E.

\section{References}

${ }^{1}$ Anonomous, "Buckling of Thin-Walled Circular Cylinders," NASA Space Vehicle Design Criteria, NASA SP8007, September 1965 (Revised 1968).

${ }^{2}$ Anonomous, "Buckling of Thin-Walled Truncated Cones," NASA Space Vehicle Design Criteria, NASA SP-8019, September 1968.

${ }^{3}$ Anonomous, "Buckling of Thin-Walled Doubly Curved Shells," NASA Space Vehicle Design Criteria, NASA SP8032, August 1969.

${ }^{4}$ Anonymous, "Isogrid Design Handbook," NASA CR-124075, February 1973.

${ }^{5}$ Thornburgh, R. P., and Hilburger, M. W., "Design of Orthogrid Cylinder Test Articles for the Shell Buckling Knockdown Factor Assessment," NASA/TM-2010-216866, November 2010.

${ }^{6}$ Thornburgh, R. P., and Hilburger, M. W., "Longitudinal Weld Land Buckling in Compression-Loaded Orthogrid Cylinders," NASA/TM-2010-216876, December 2010.

${ }^{7}$ Hilburger, M.W., Lovejoy, A.E., Thornburgh, R.P., and Rankin, C., " Design and Analysis of Subscale and FullScale Buckling-Critical Cylinders for Launch Vehicle Technology Development," $53^{\text {rd }}$

AIAA/ASME/ASCE/AHS/ASC Structures, Structural Dynamics, and Materials Conference, Honolulu, HI, Apr. 23$26,2012$.

${ }^{8}$ Hilburger, M. W., "Static Buckling Tests of Aerospace Vehicle Structures," NASA/TM-2010-216849, October 2010. 


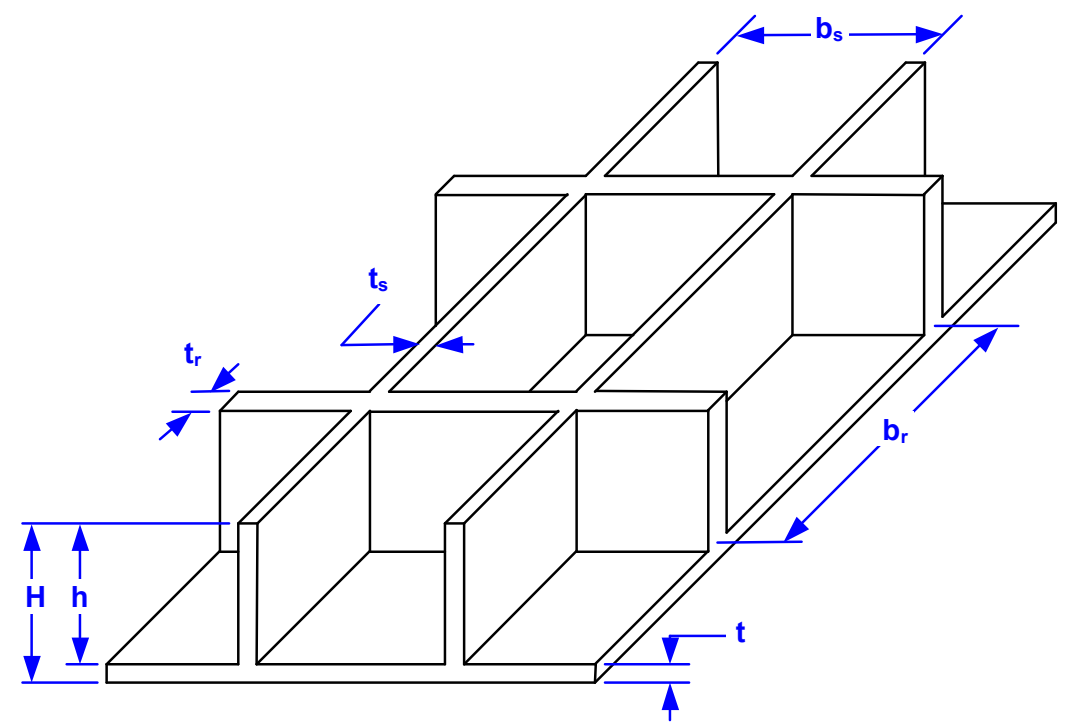

Figure 1. Orthogrid stiffener pattern and nomenclature.

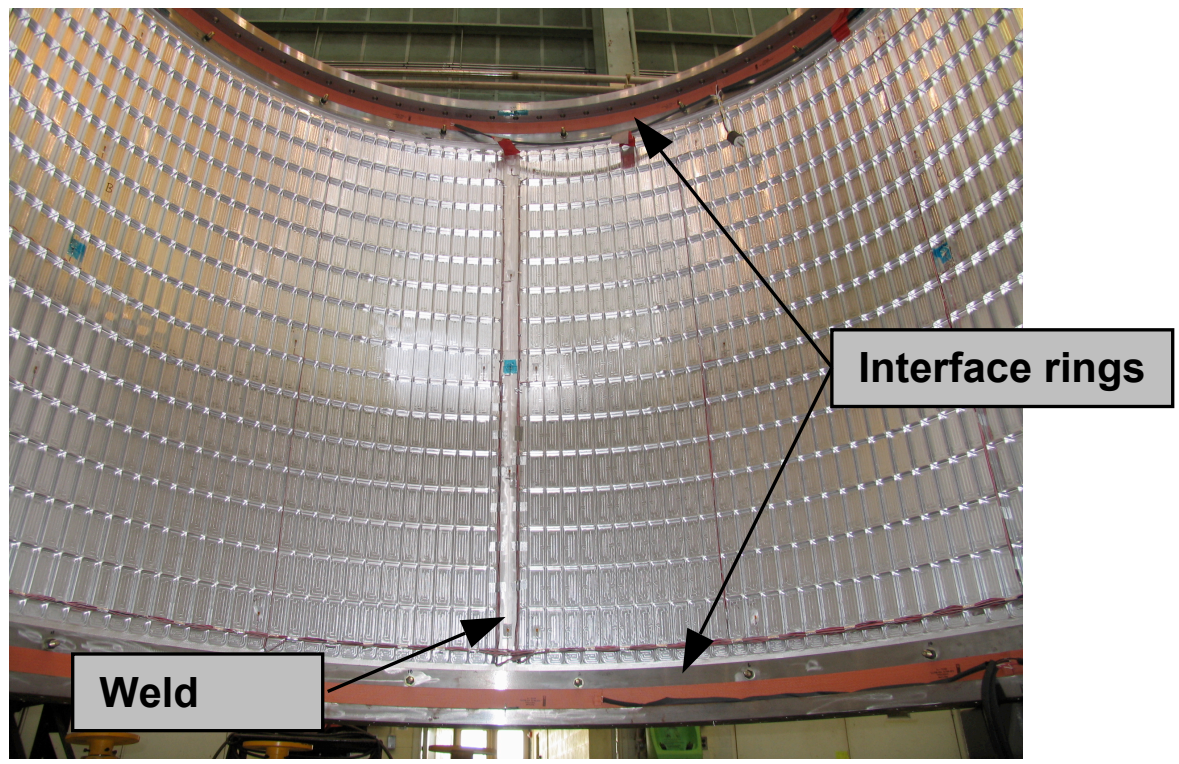

Figure 2. Internal view of an integrally-machined stiffener pattern of a typical aluminum orthogrid-stiffened test article, including a longitudinal weld land detail (vertical unstiffened weld land in the center of the image) and interface rings. 


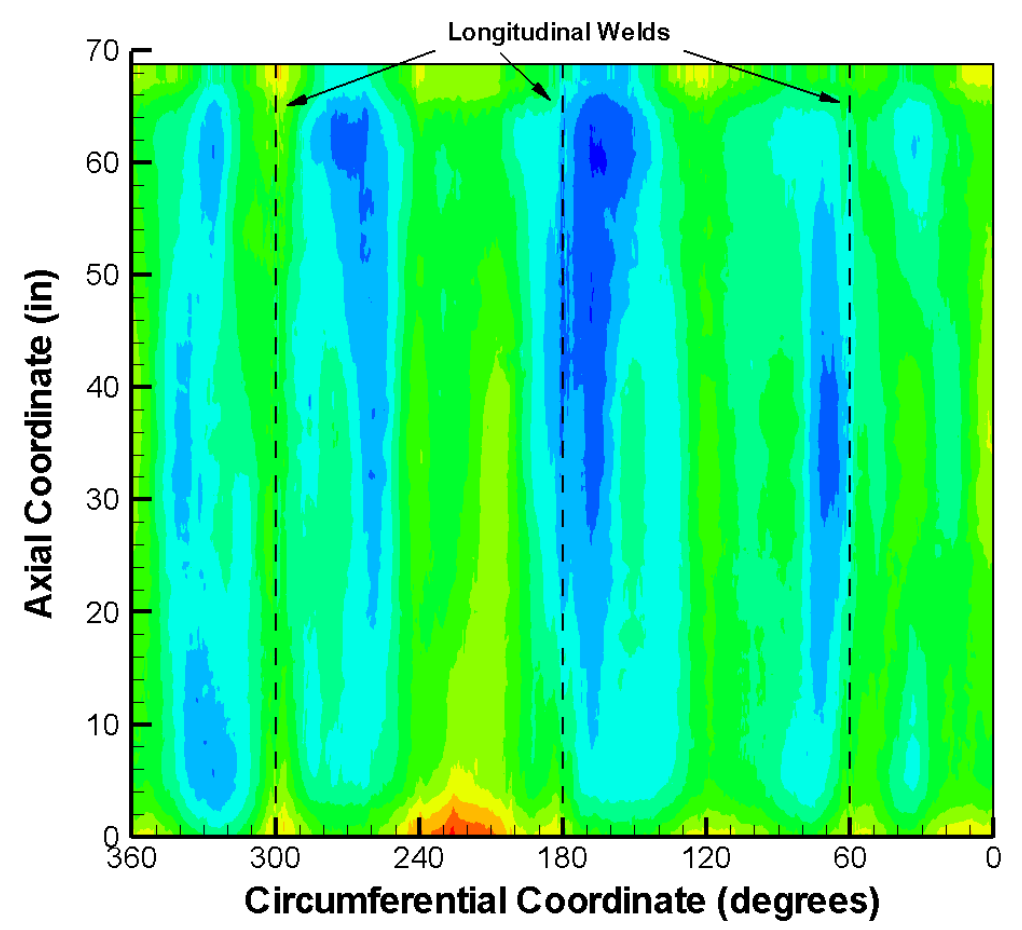

Figure 3. Typical contour plot of a measured geometric imperfection of an 8-ft-diameter orthogrid-stiffened shell with three longitudinal welds (blue and red contours correspond to inward and outward radial imperfections, respectively. Dashed vertical lines indicate longitudinal weld land locations).

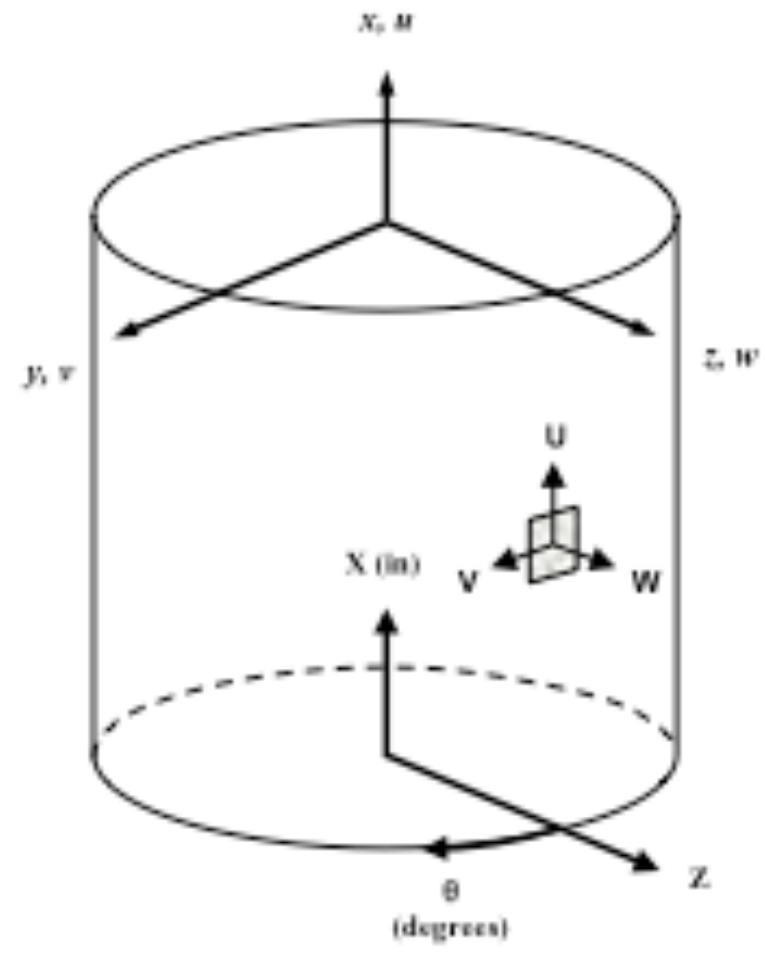

Figure 4. Test article coordinate systems. Surface coordinate system (cylindrical coordinates) $X, \Theta, Z$ with displacements $\mathrm{u}, \mathrm{v}, \mathrm{w}$. Global and loading coordinates $x, y, z$ and displacements $u, v, w$ and rotations $\mathrm{r} x, \mathrm{r} y, \mathrm{r} z$ about the $x, y, z$ axes (not sown for clarity). 


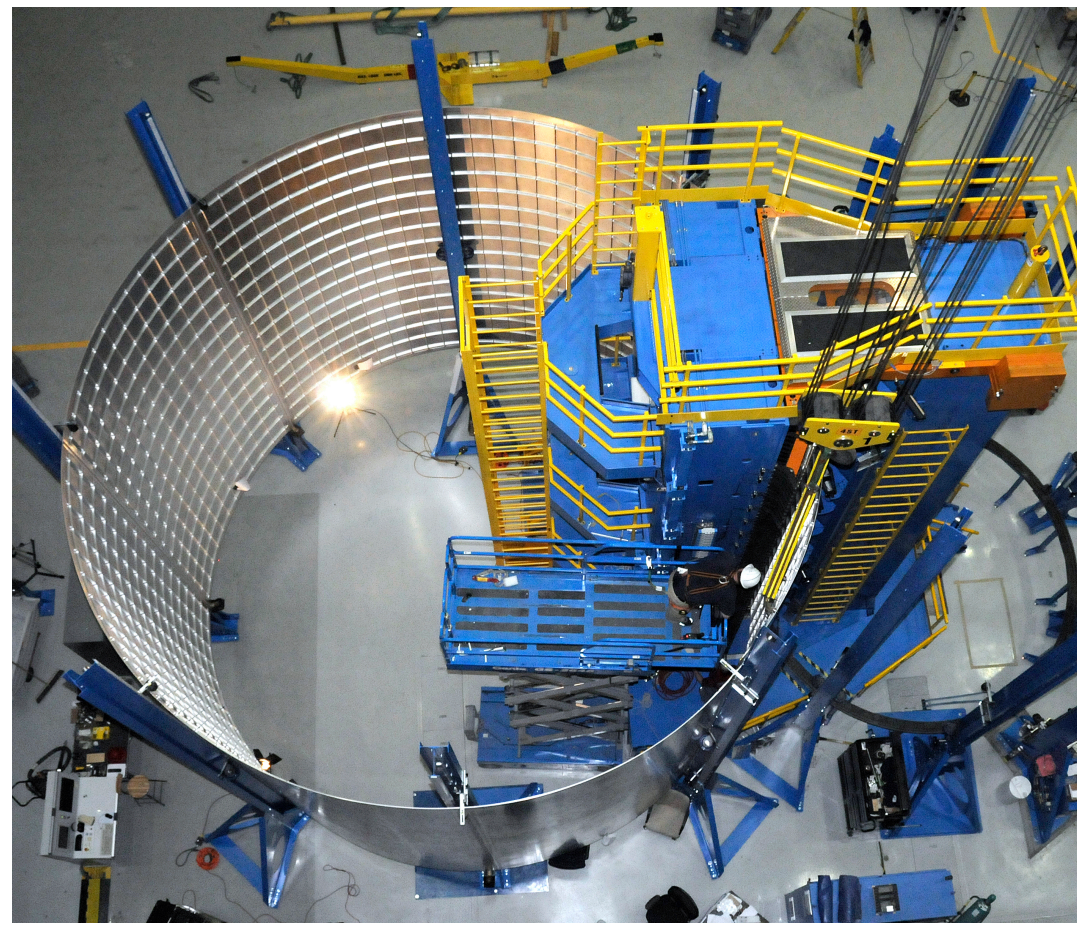

Figure 5. View of ETTA1 test article during fabrication in MSCF vertical weld tool.

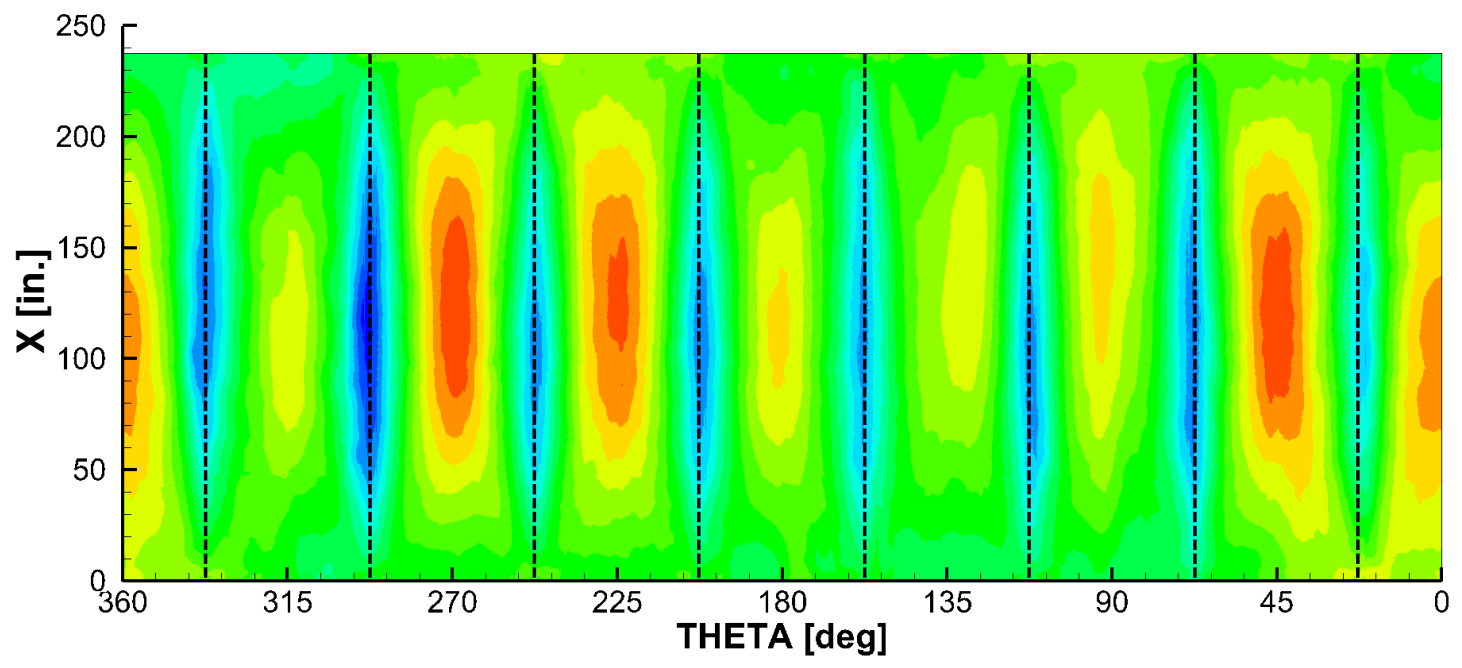

Figure 6. Typical contour plot of a measured geometric imperfection of a 27.5-ft-diameter orthogrid-stiffened shell with eight longitudinal welds (blue and red contours correspond to inward and outward radial imperfections, respectively, and vertical dashed lines indicate weld land locations). 


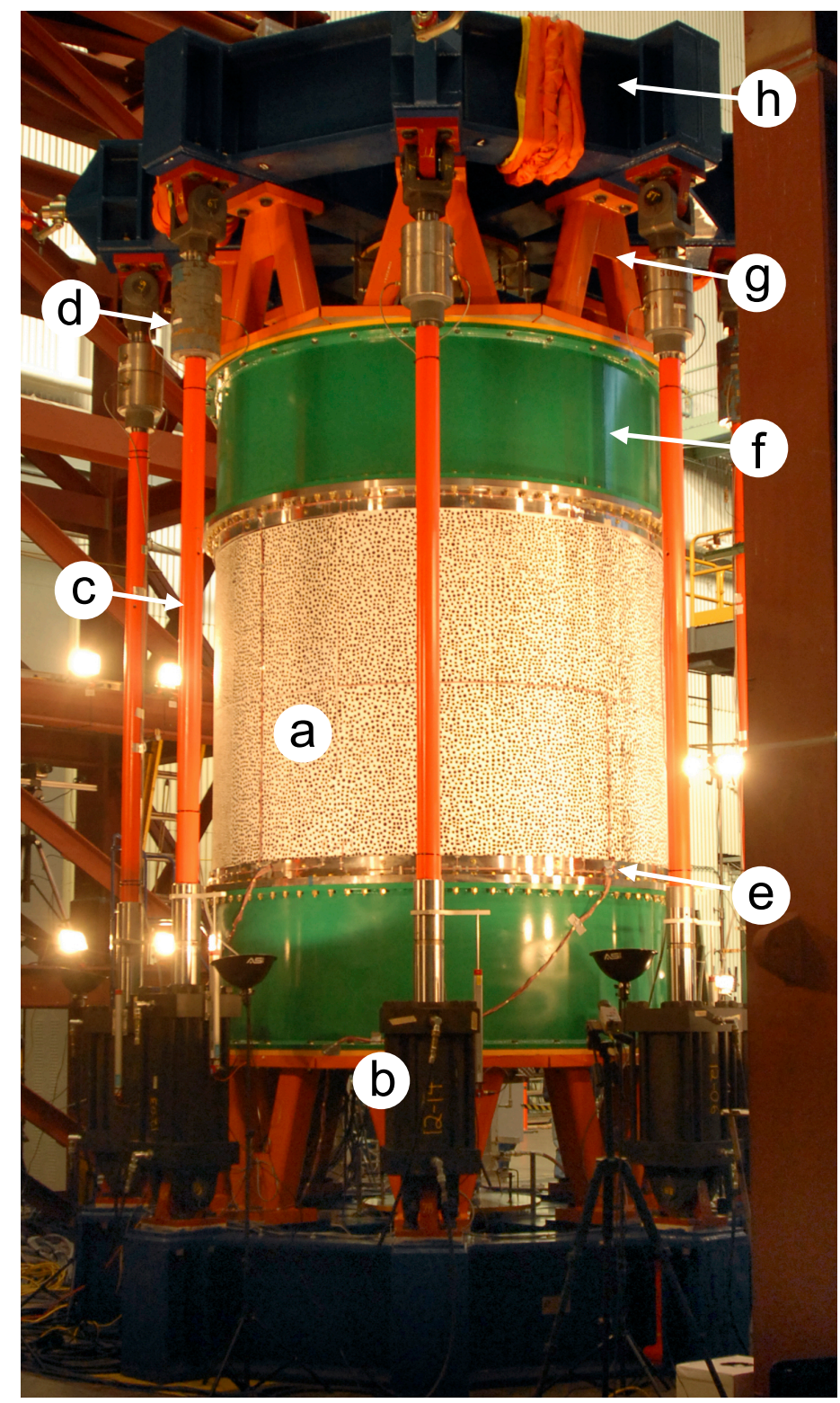

Figure 7. Eight-ft-diameter shell buckling test facility at MSFC. a) test article, b) hydraulic actuator, c) loading rod, d) load cell, e) interface ring, f) load introduction cylinder, g) strut, h) loading spider. 


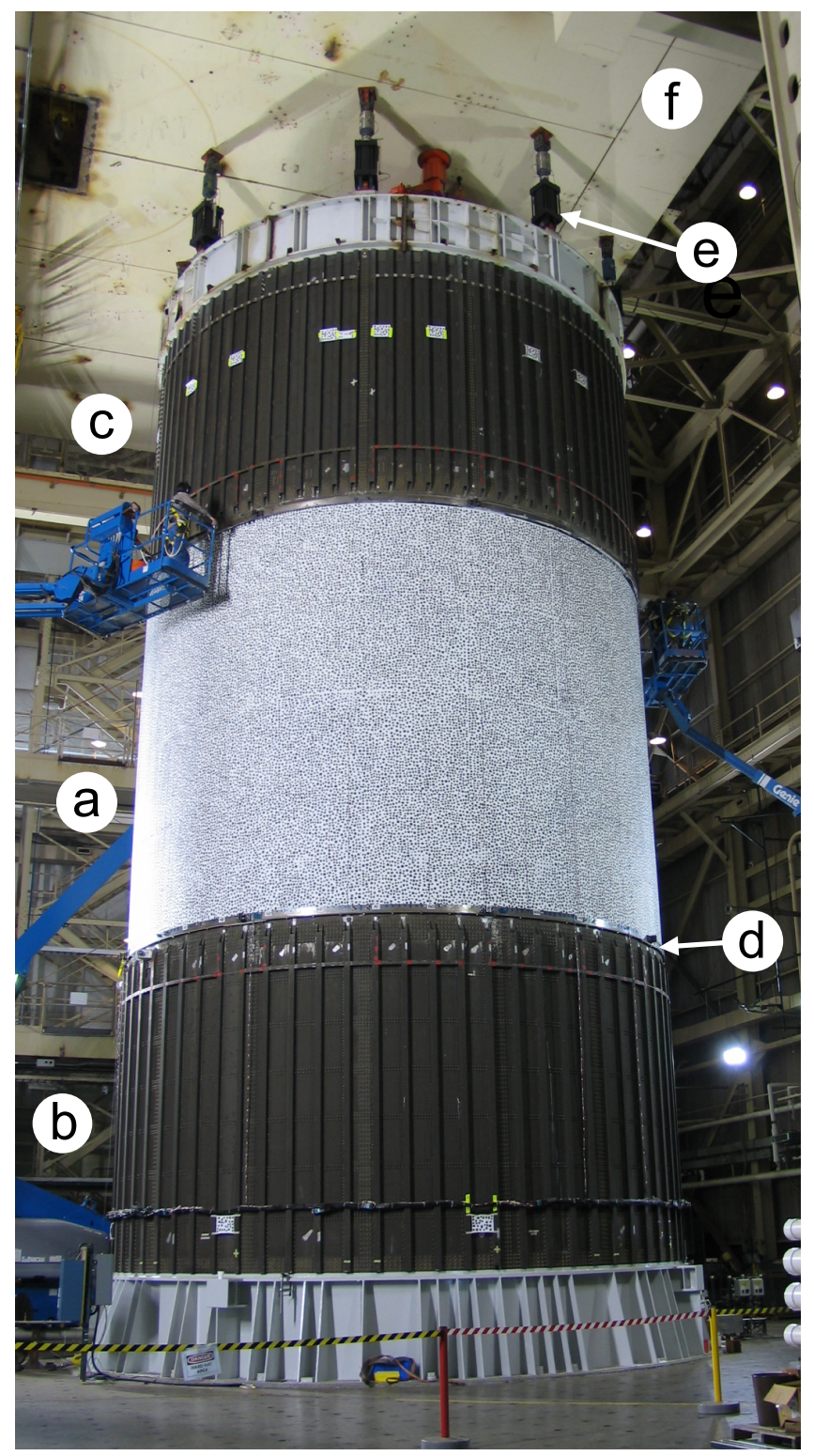

Figure 8. 27.5-ft-diameter shell buckling test facility at MSFC. a) test article, b) lower load introduction cylinder, c) upper load introduction cylinder, d) interface ring, e) hydraulic actuator, f) cross head (reaction platen) 


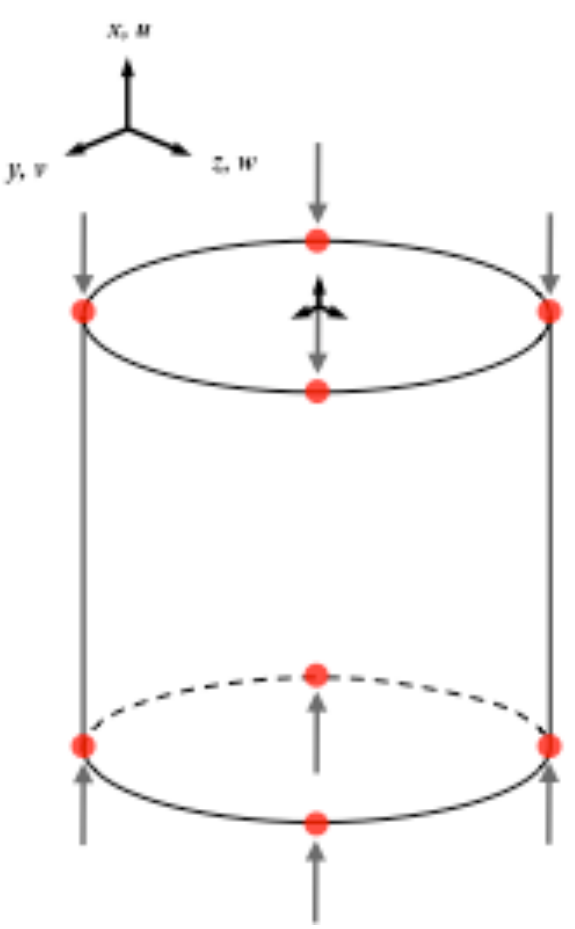

a) axial displacement measurement locations.

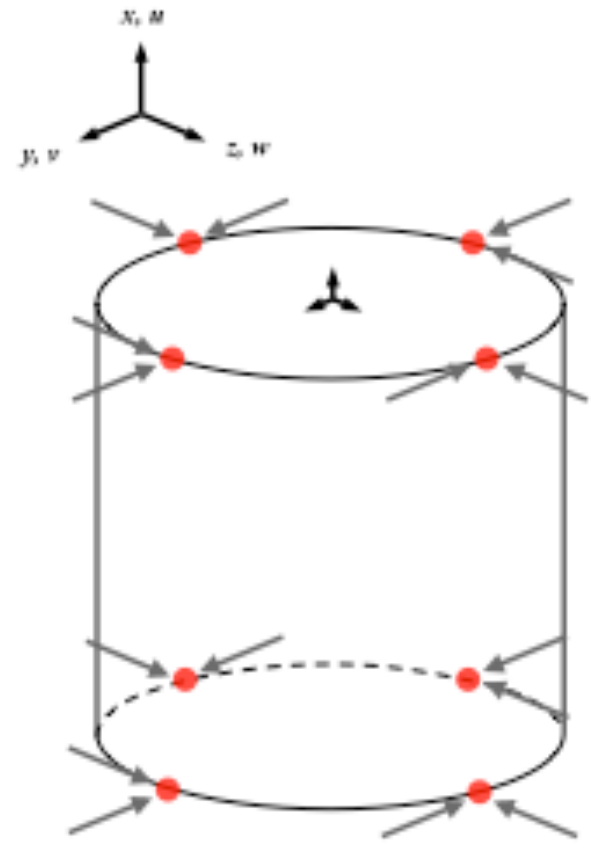

b) transverse displacement measurement locations.
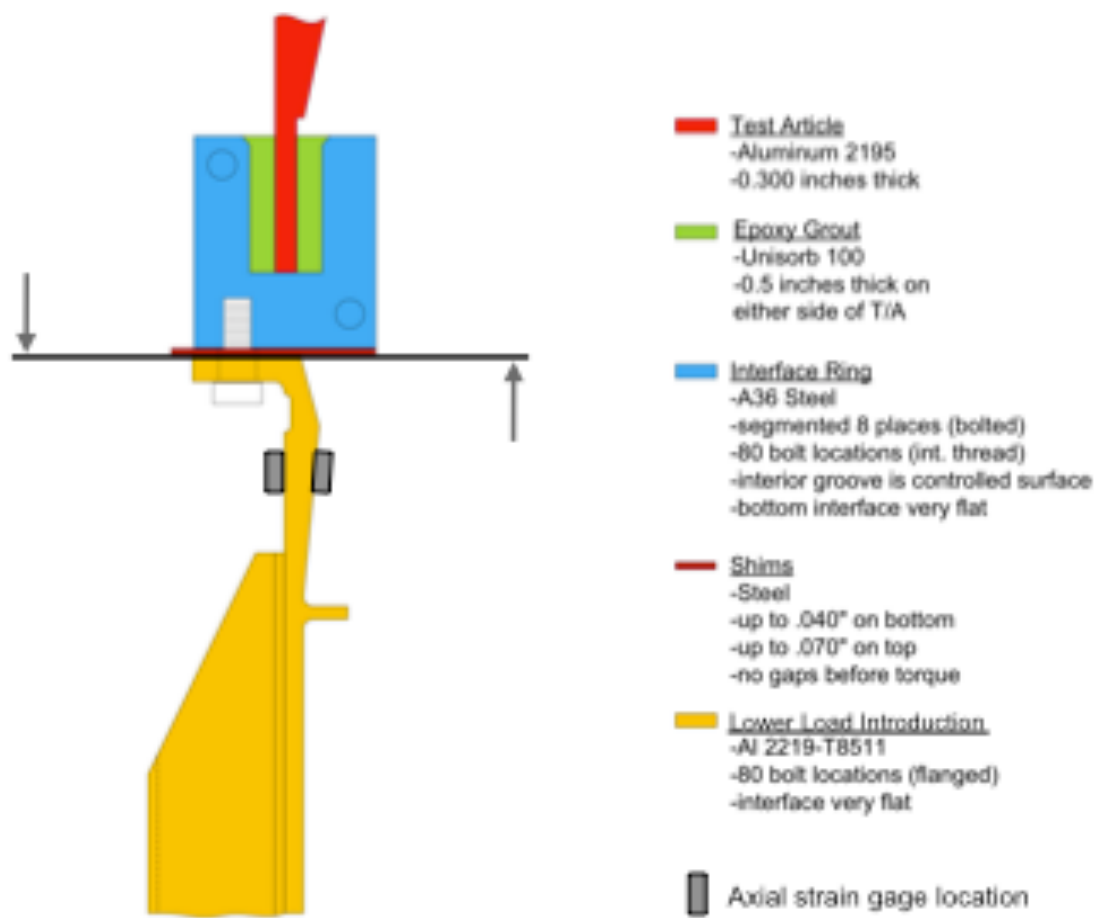

Axial strain gage location

c) Cross-sectional view of ETTA1 interface ring indicating rotation measurements and back-to-back strains taken at each of the locations shown in Fig. 9a (representative of ETTA1 only).

Figure 9. Typical displacement measurement locations on upper and lower TA interface rings. 


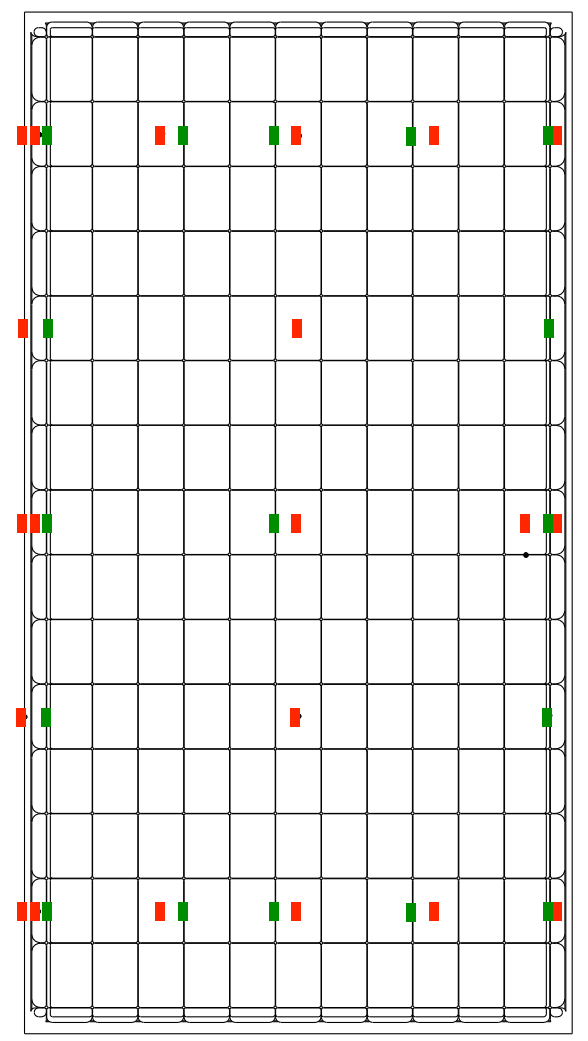

- Skin gage

I Stiffener gage

Figure 10. Typical back-to-back strain gage locations on an orthogrid-stiffened TA barrel panel segment. 


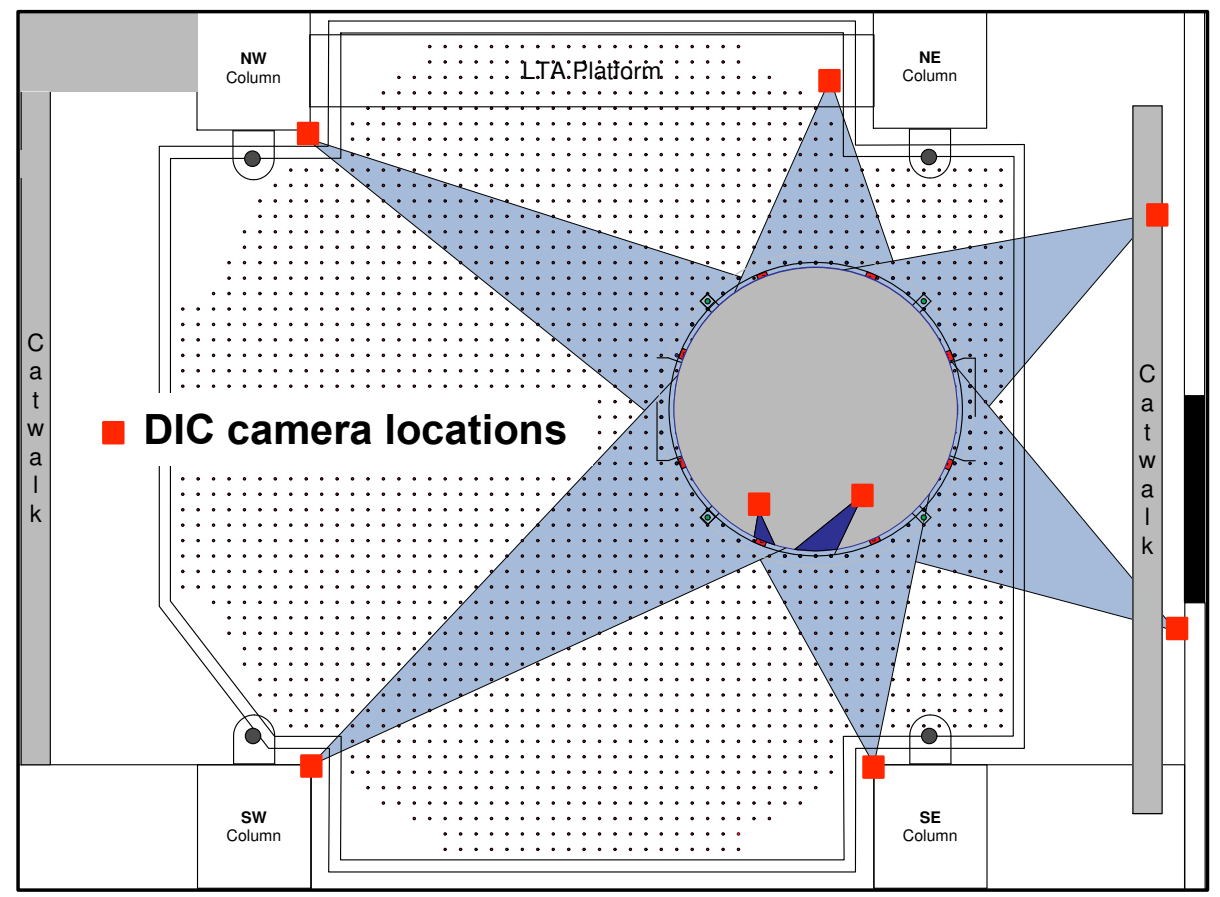

Figure 11. Top view of internal and external DIC camera systems (indicated by red squares) and viewing areas (indicated by the shaded blue regions) for the ETTA1 test (similar external DIC set-up was used on all 8-ft-diameter test articles, including TA01).

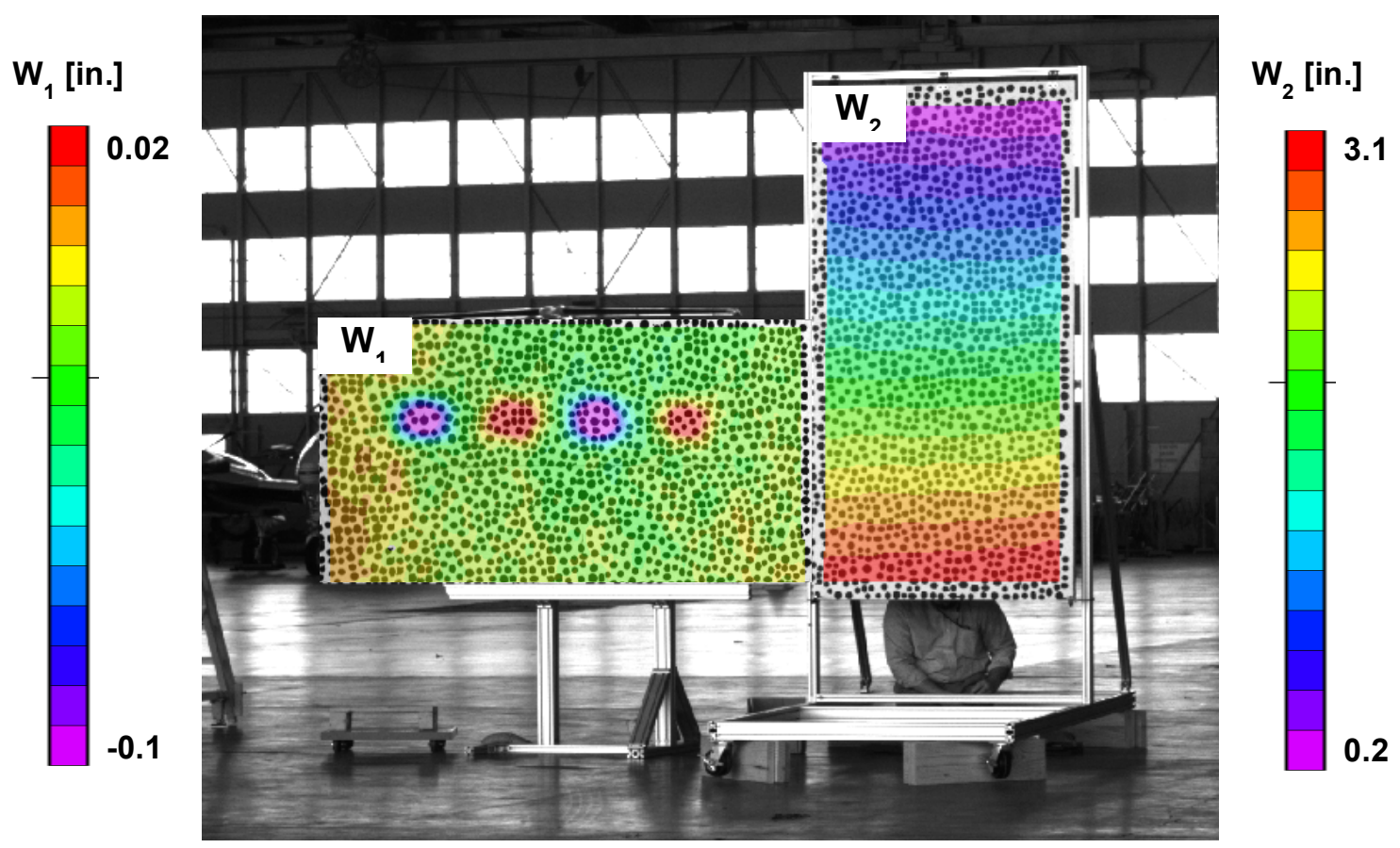

Figure 12. Typical measured displacement contours obtained from a DIC measurement resolution verification study. $W_{1}$ contours from local skin buckling measurement resolution study. $W_{2}$ contours from global displacement resolution study. 


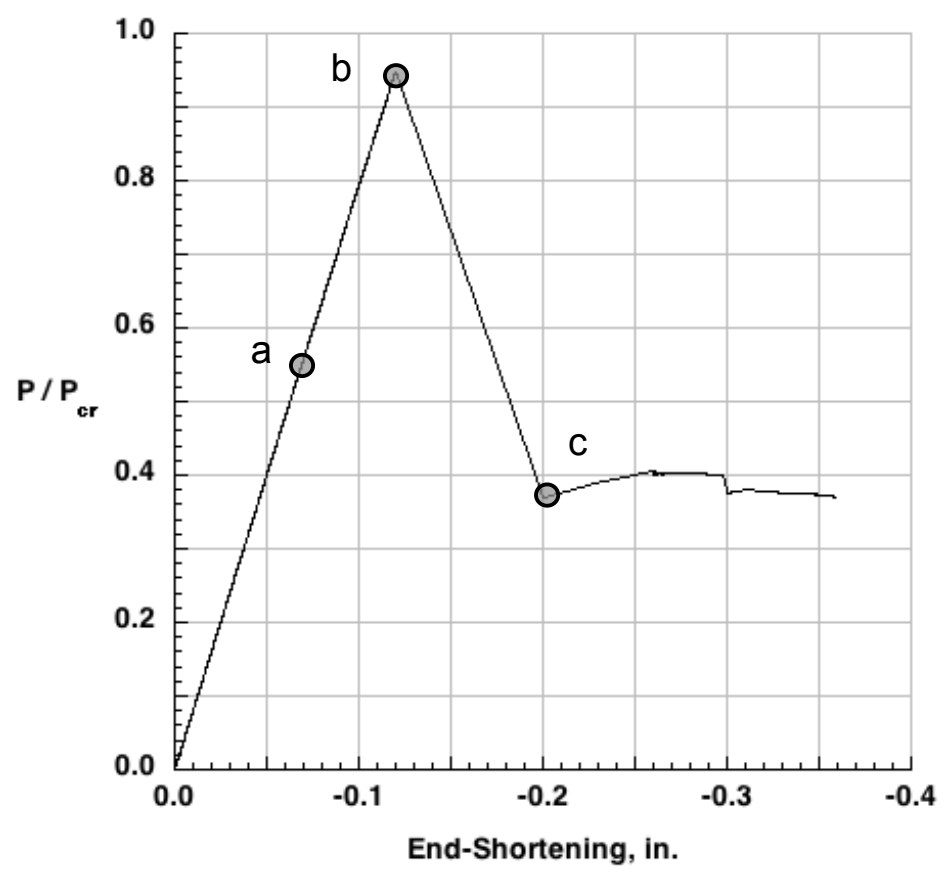

Figure 13. Load versus end-shortening response for TA01 subjected to axial compression.

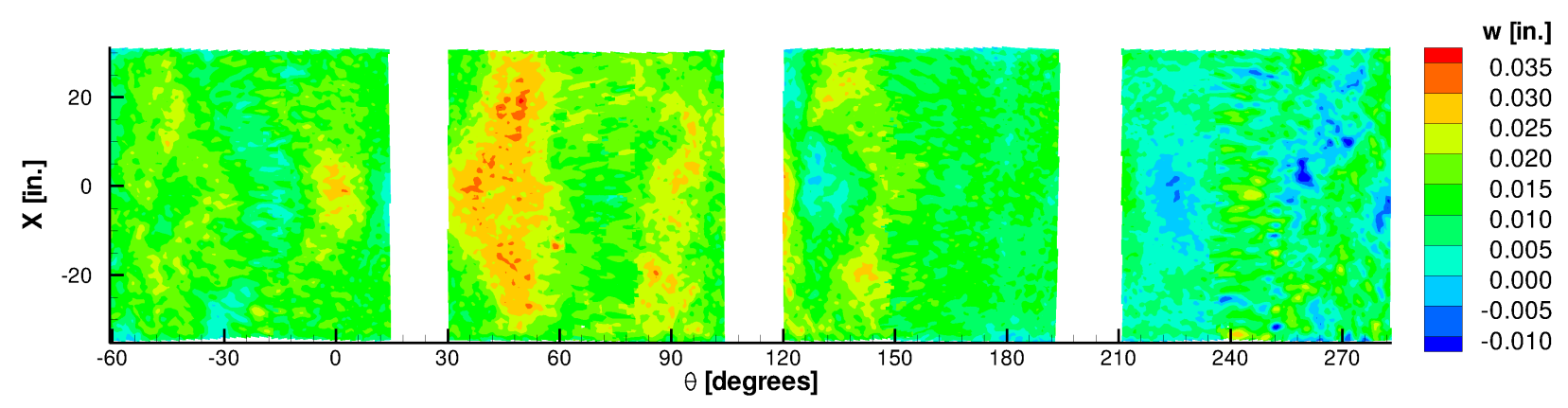

Figure 14. Measured pre-buckling radial displacement contours at point $a$ in Fig. 13, $P / P_{c r}=0.55$.

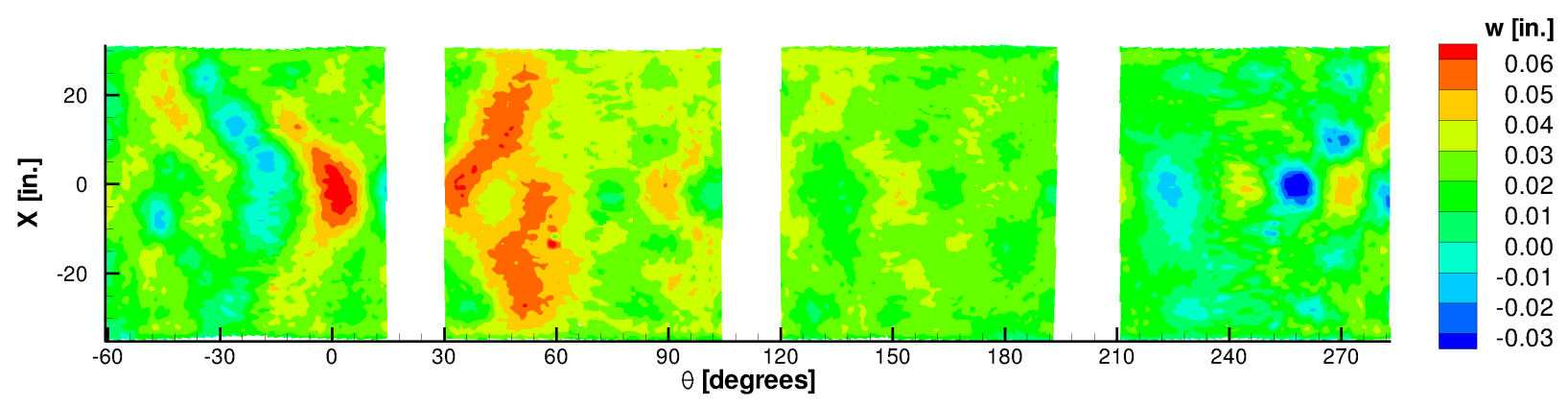

Figure 15. Measured incipient buckling radial displacement contours at point $b$ in Fig. 13, $P / P_{c r}=0.95$. 


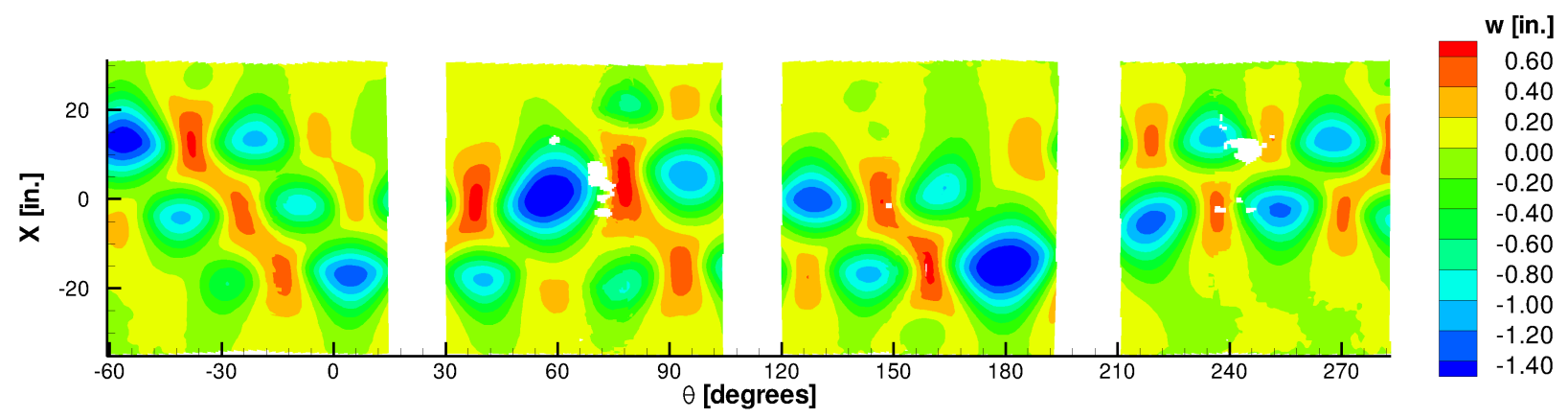

Figure 16. Initial post-buckling radial displacement contours at point $C$ in $F i g .13, P / P_{c r}=0.38$.

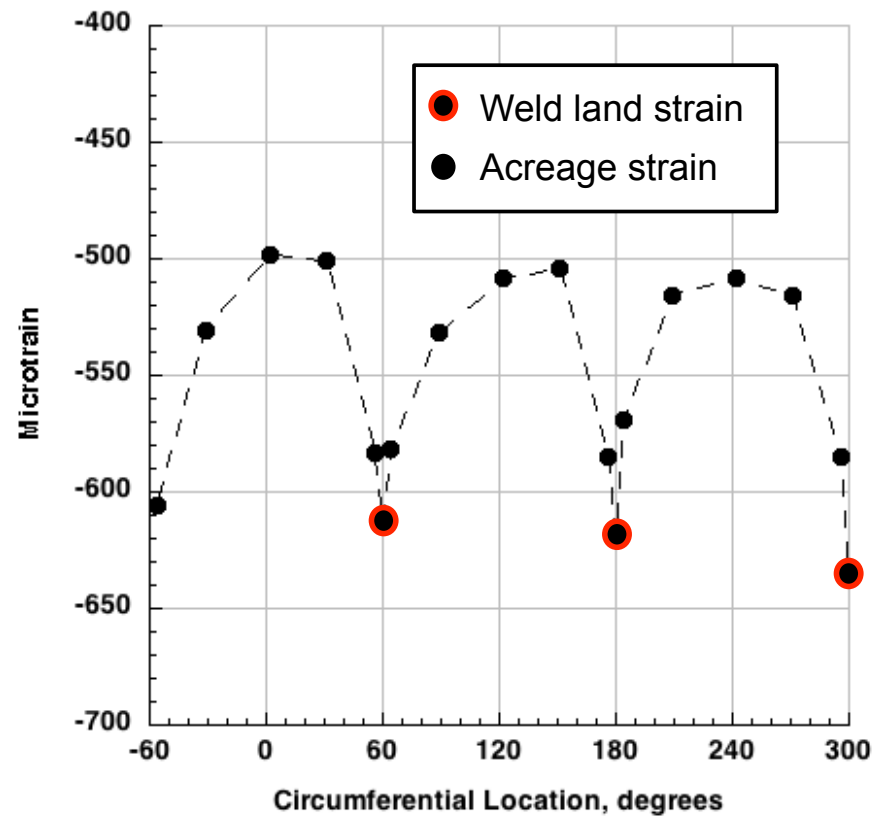

Figure 17. Typical axial strains around circumference of TA01 at $40 \%$ Pcr. 


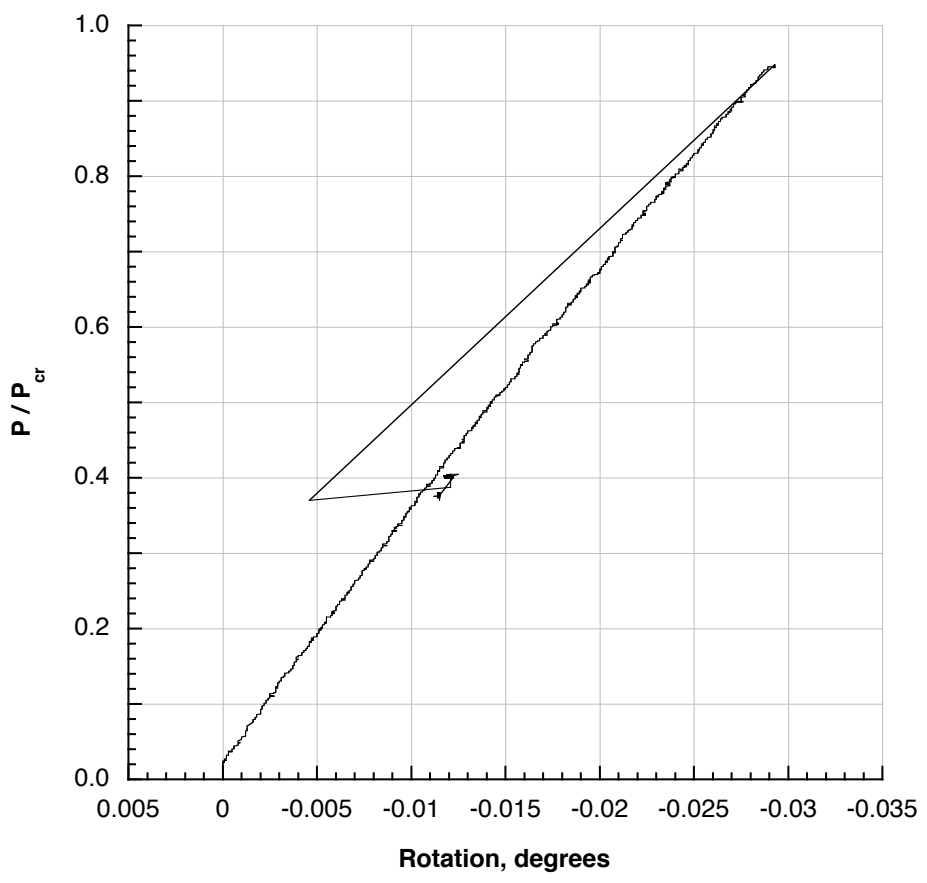

Figure 18. Load versus torsion displacement response for TA01 subjected to axial compression.

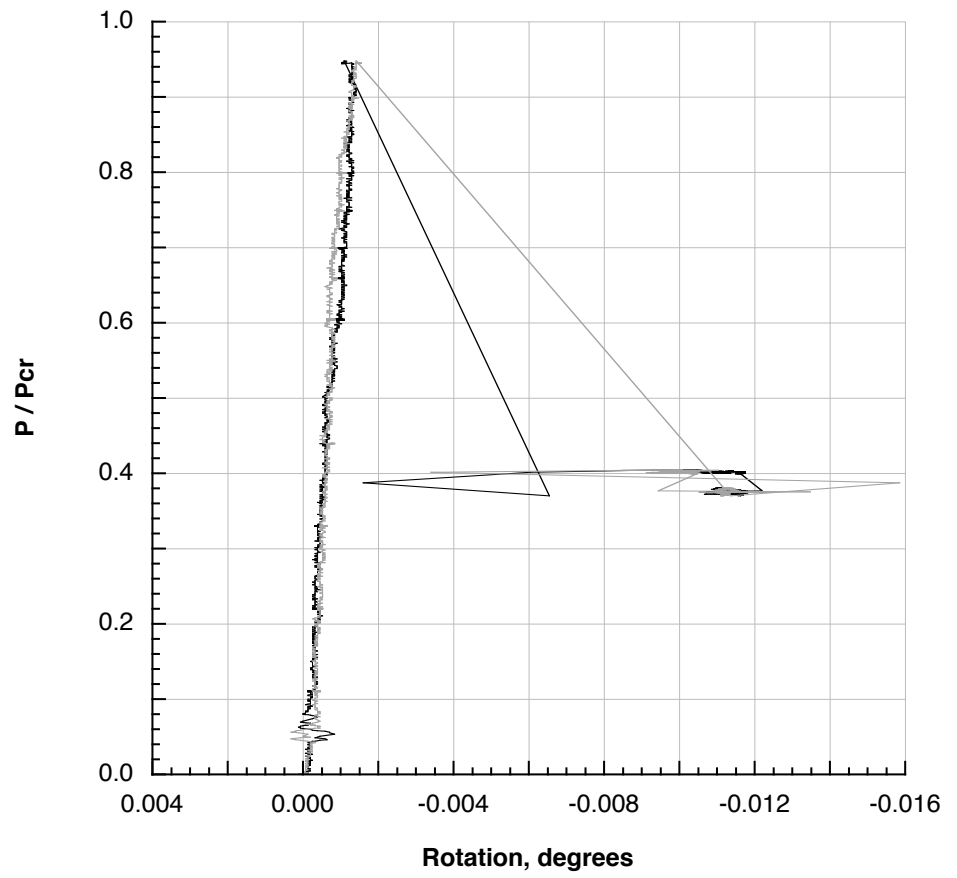

Figure 19. Load versus bending displacement response for TA01 subjected to axial compression. 


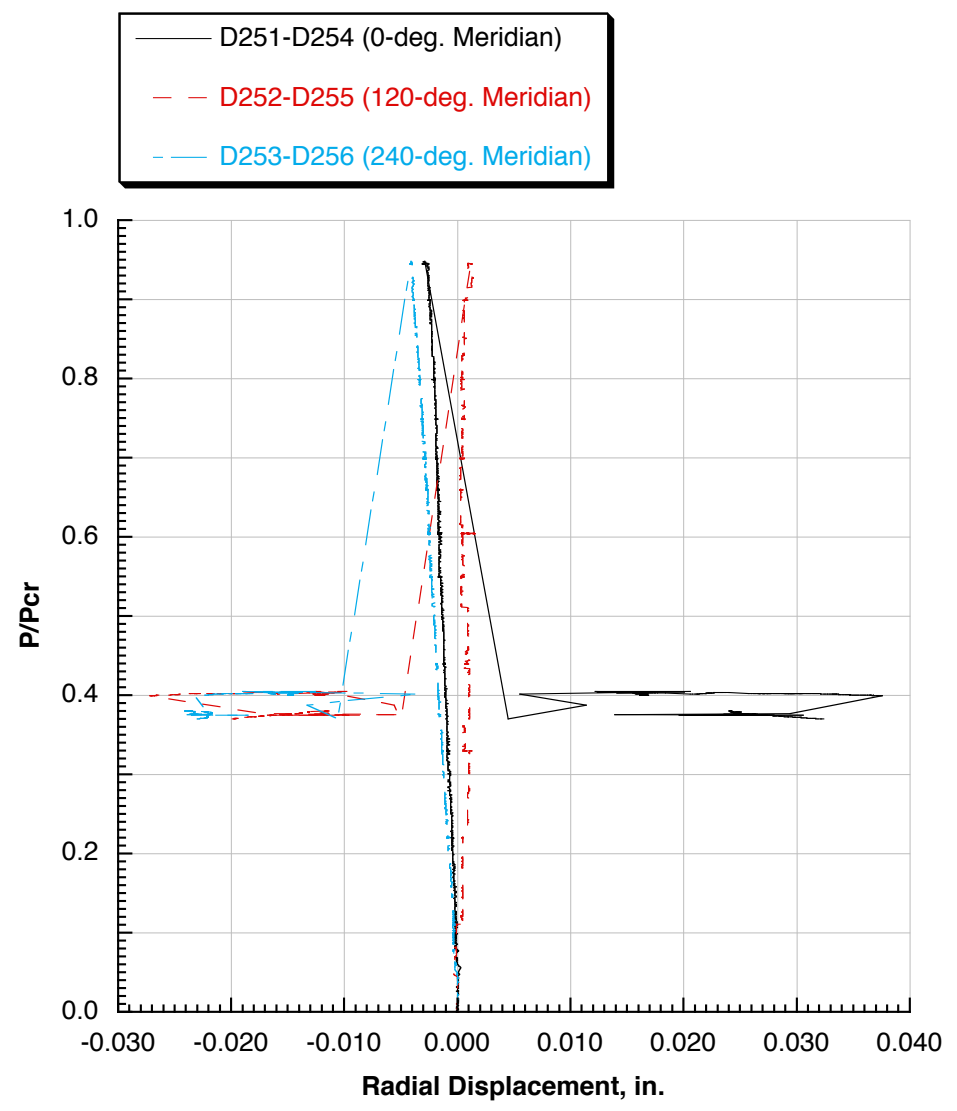

Figure 20. Load versus transverse displacement response for TA01 subjected to axial compression. 


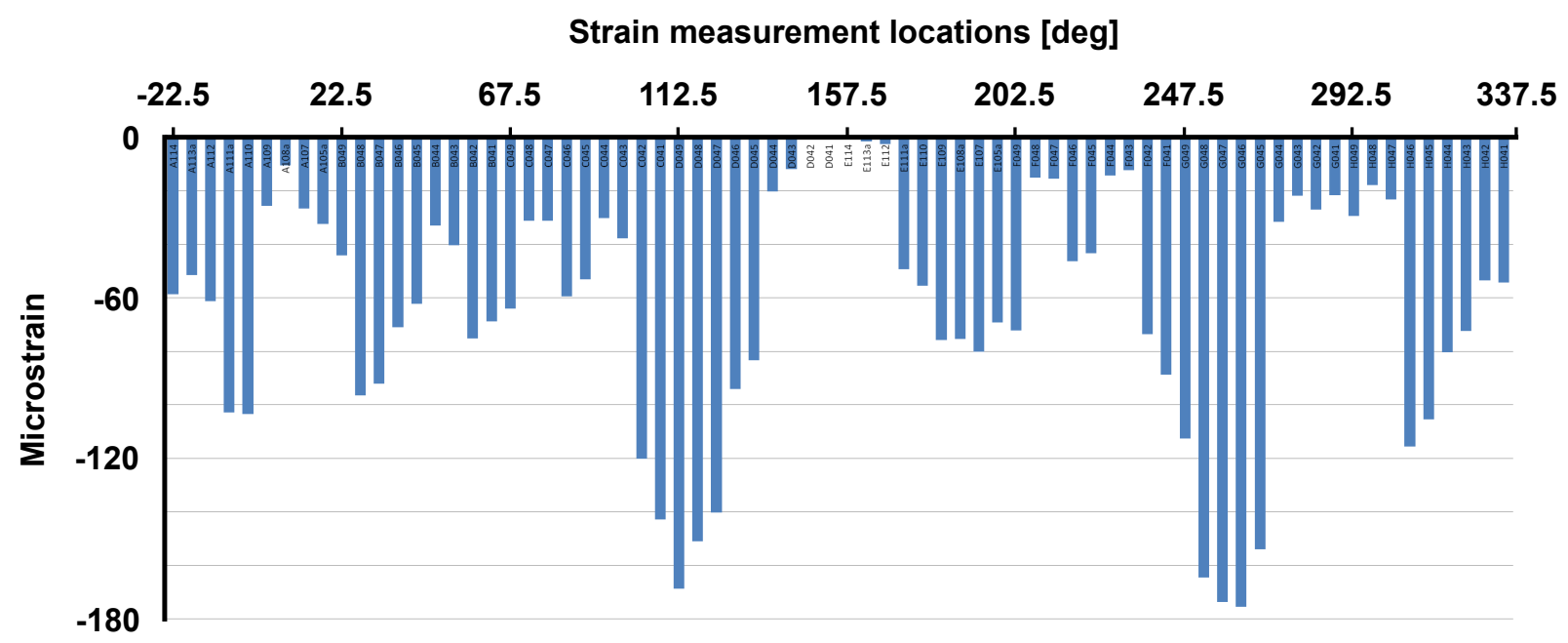

a) pre-interface-shimming strain response at the top of ETTA1.

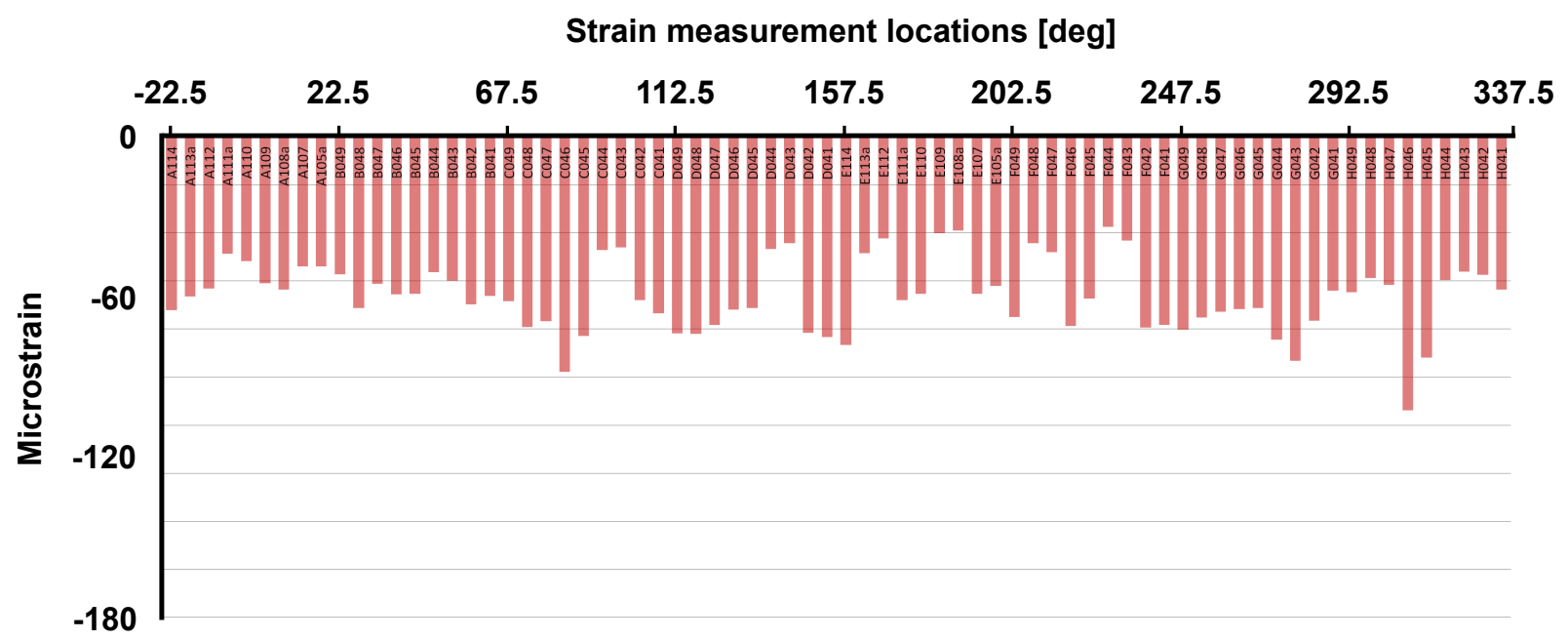

b) post-interface-shimming strain response at the top of ETTA1.

Figure 21. Pre- and post-interface-shimming axial strain distribution at the top of ETTA1 subjected to 80,000lb of compression. 


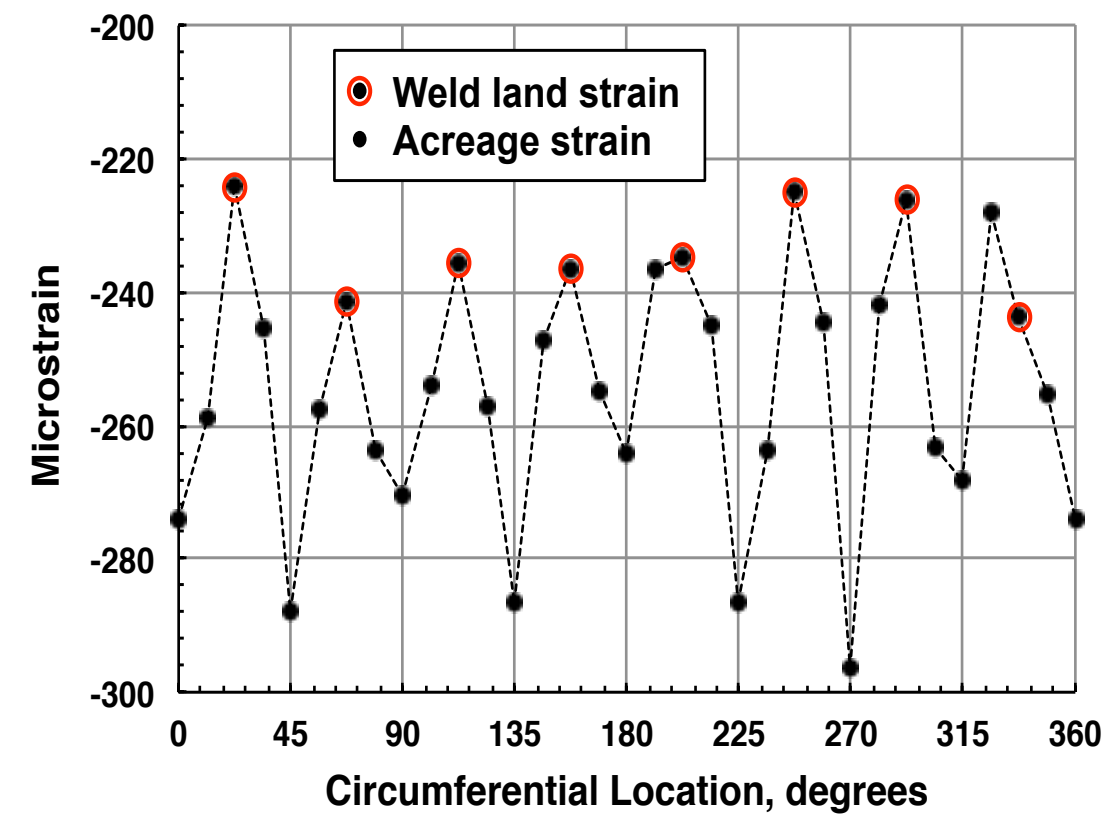

Figure 22. Typical measured axial strain distribution around circumference of ETTA1 at $P / P_{c r}=0.45$.

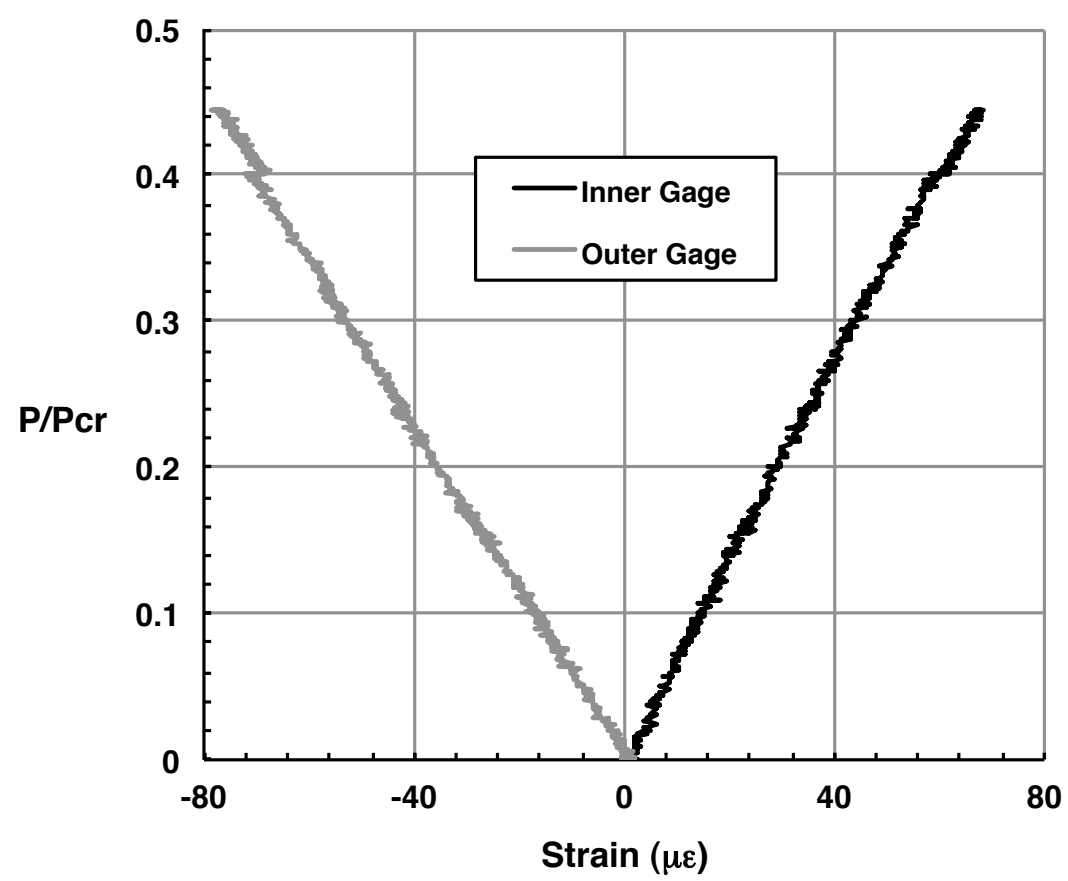

Figure 23. Typical load versus strain response for back-to-back axial strains near bottom simulator to ETTA1 interface (see Fig. 9c for typical measurement location). 


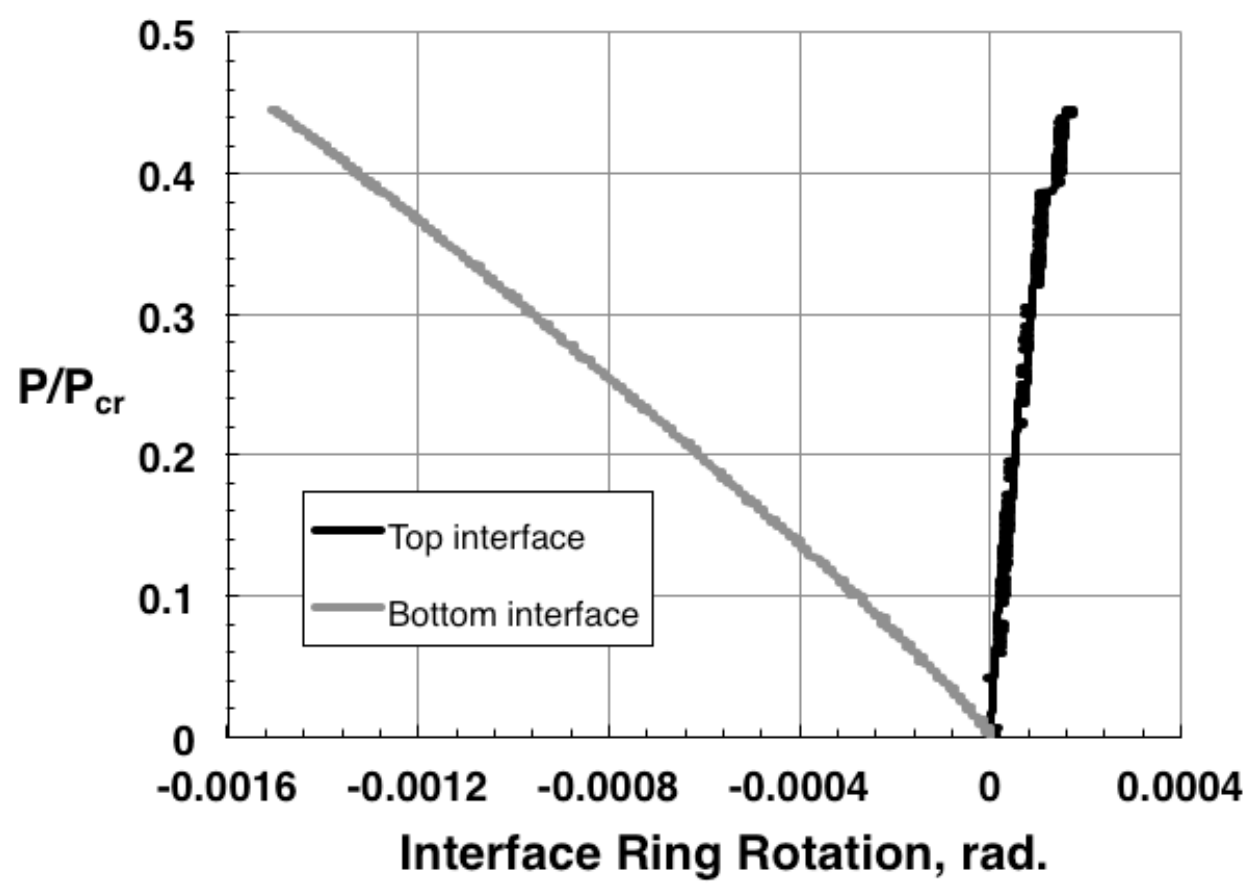

Figure 24. Typical load versus rotation response of simulator to ETTA1 interface (see Fig. 9c for measurement location).

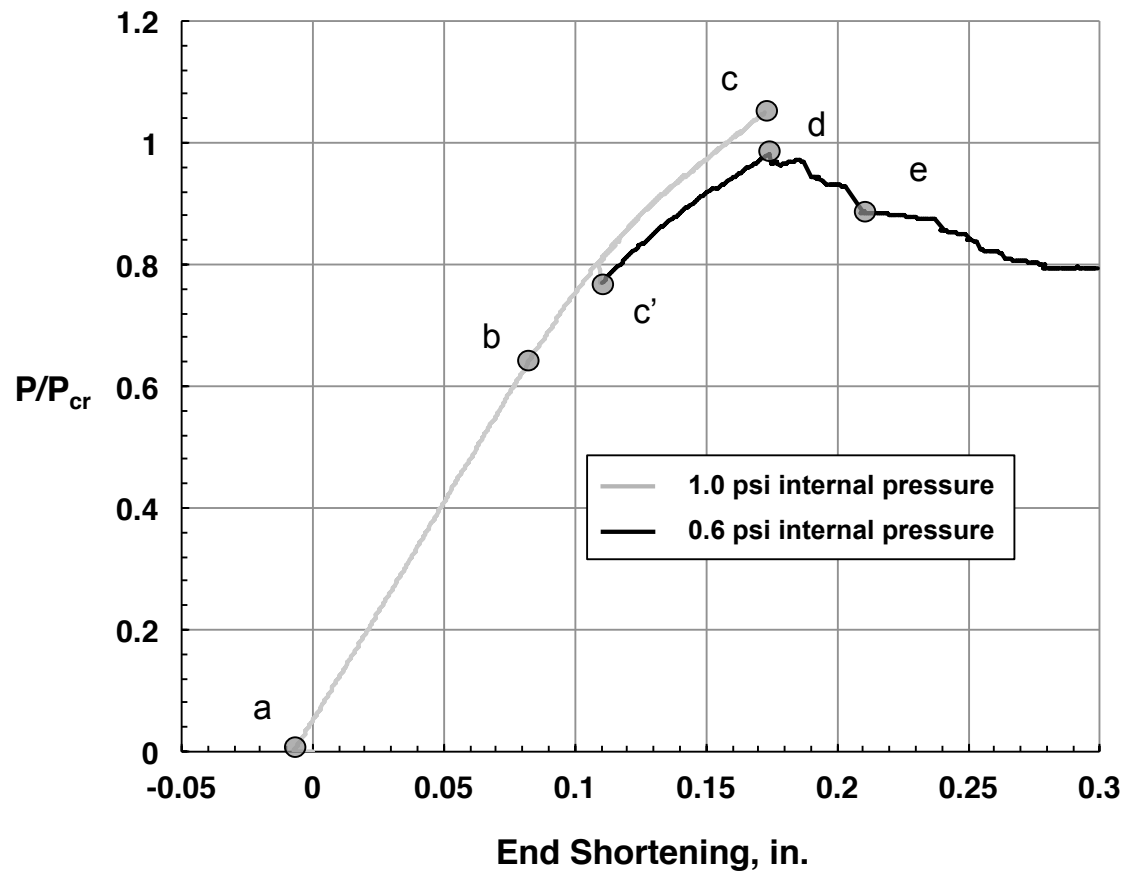

Figure 25. Load-end-shortening response curve for ETTA1 subjected to combined internal pressure and axial compression loads. a - initial pressurization to 1.0 psi. b - local skin-pocket buckling. c - maximum load. $\mathrm{d}$ - initial weld land buckling, 0.6 psi internal pressure. e - weld land buckling complete. 


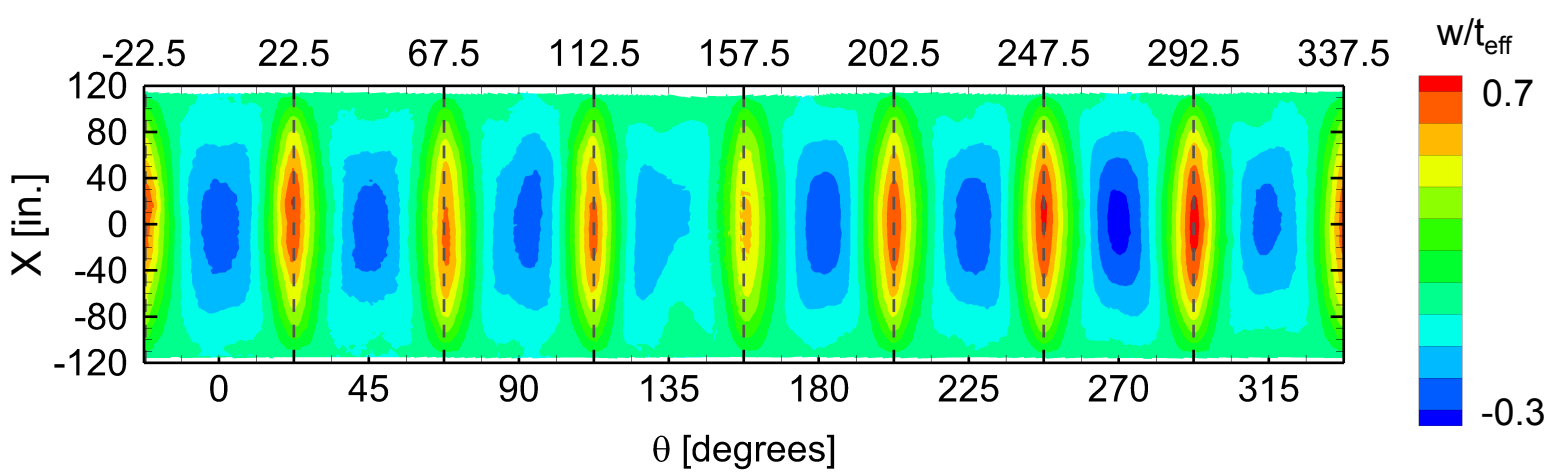

a) normalized radial displacement

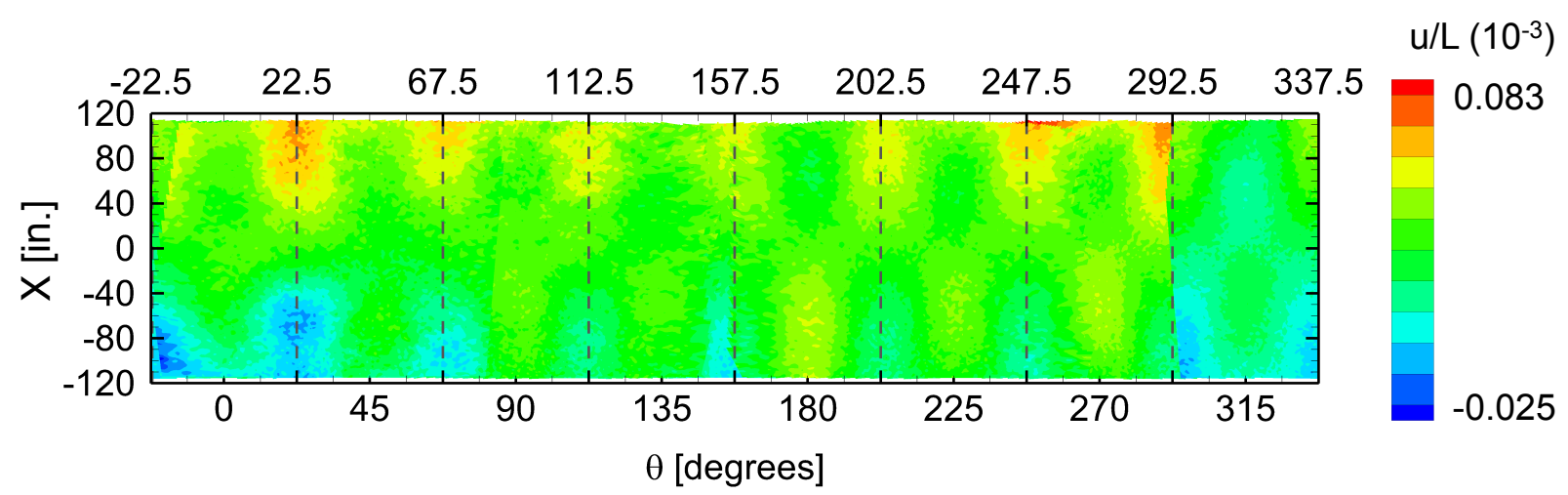

b) normalized axial displacement

Figure 26. Measured displacement contours for ETTA1 subjected to 1.0 psi internal pressure, corresponding to loading point a in Figure 25. (dashed lines indicate the location of longitudinal weld lands) 


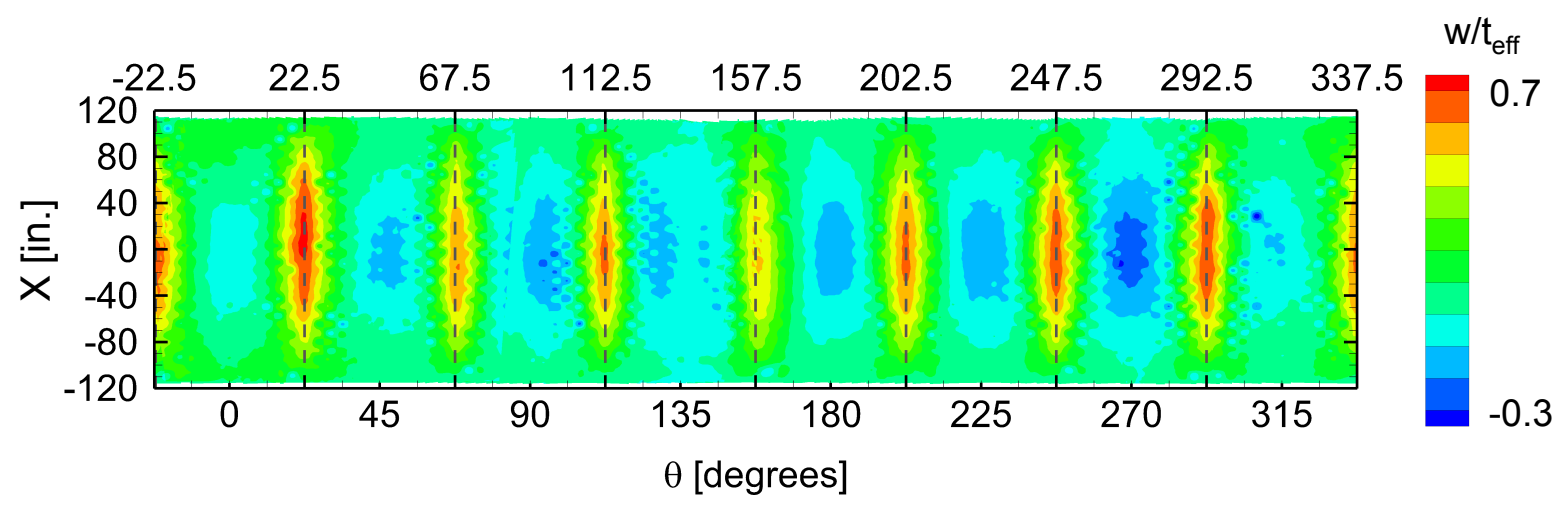

a) normalized radial displacement

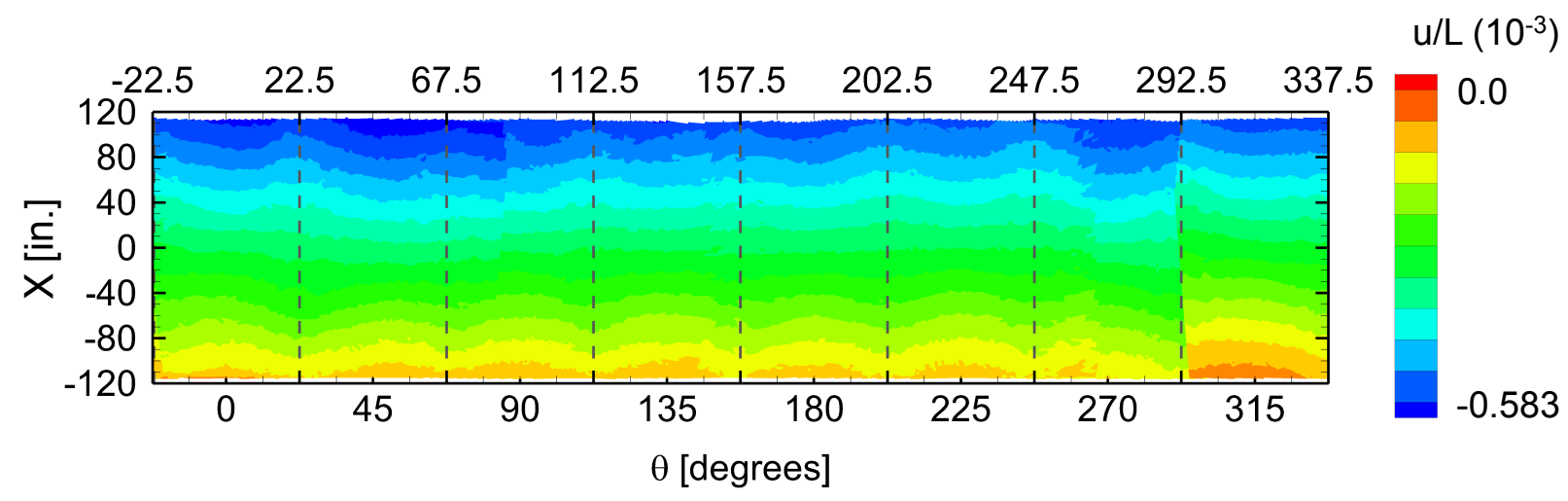

b) normalized axial displacement

Figure 27. Measured displacement contours for ETTA1 subjected to 1.0 psi internal pressure and a compression load of $80 \%$ Pcr, corresponding to loading point b in Figure 25. (dashed lines indicate the location of longitudinal weld lands) 


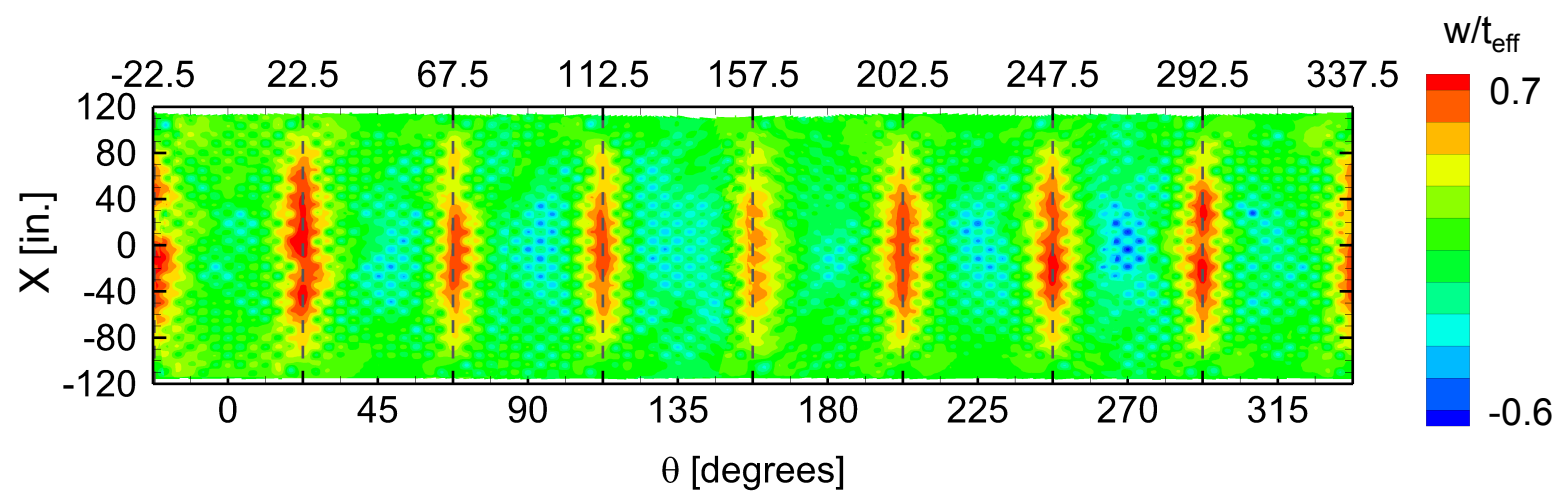

a) normalized radial displacement

$\mathrm{u} / \mathrm{L}\left(10^{-3}\right)$

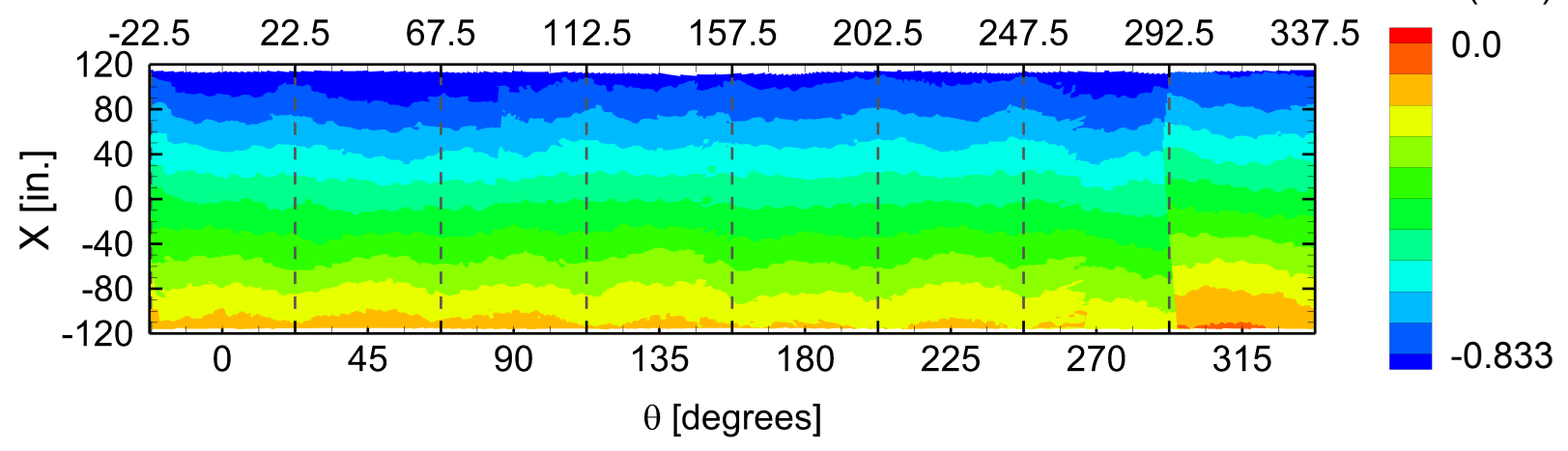

b) normalized axial displacement

Figure 28. Measured displacement contours for ETTA1 subjected to 1.0 psi internal pressure and a compression load of 104\% Pcr, corresponding to loading point $\mathrm{c}$ in Figure 25. (dashed lines indicate the location of longitudinal weld lands) 


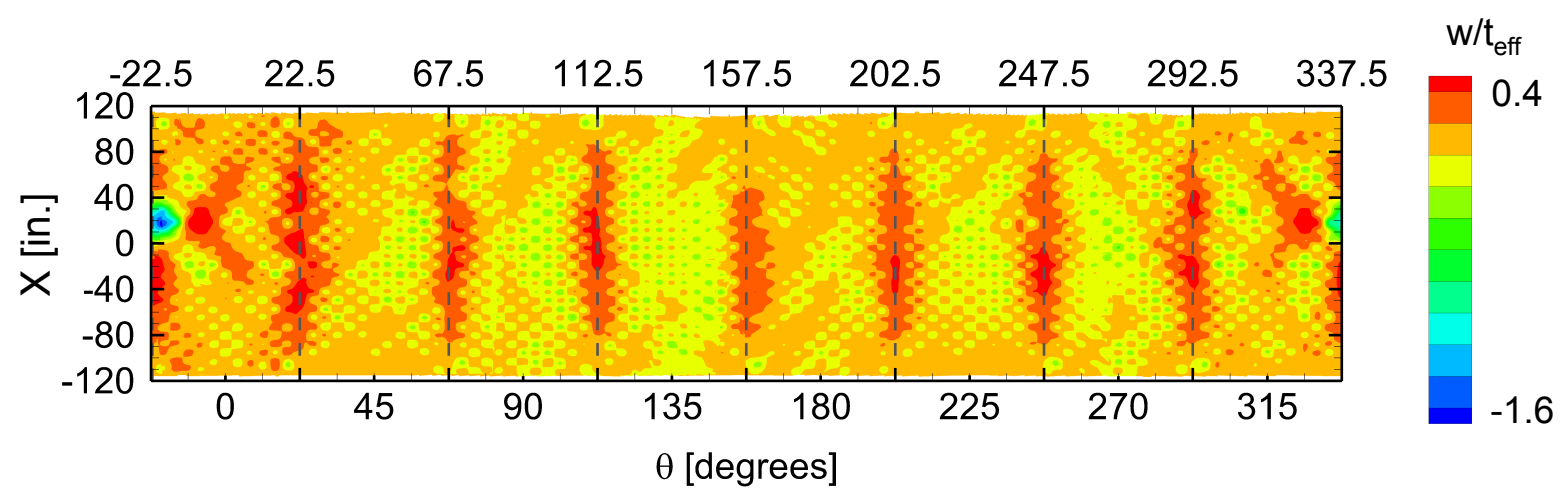

a) normalized radial displacement

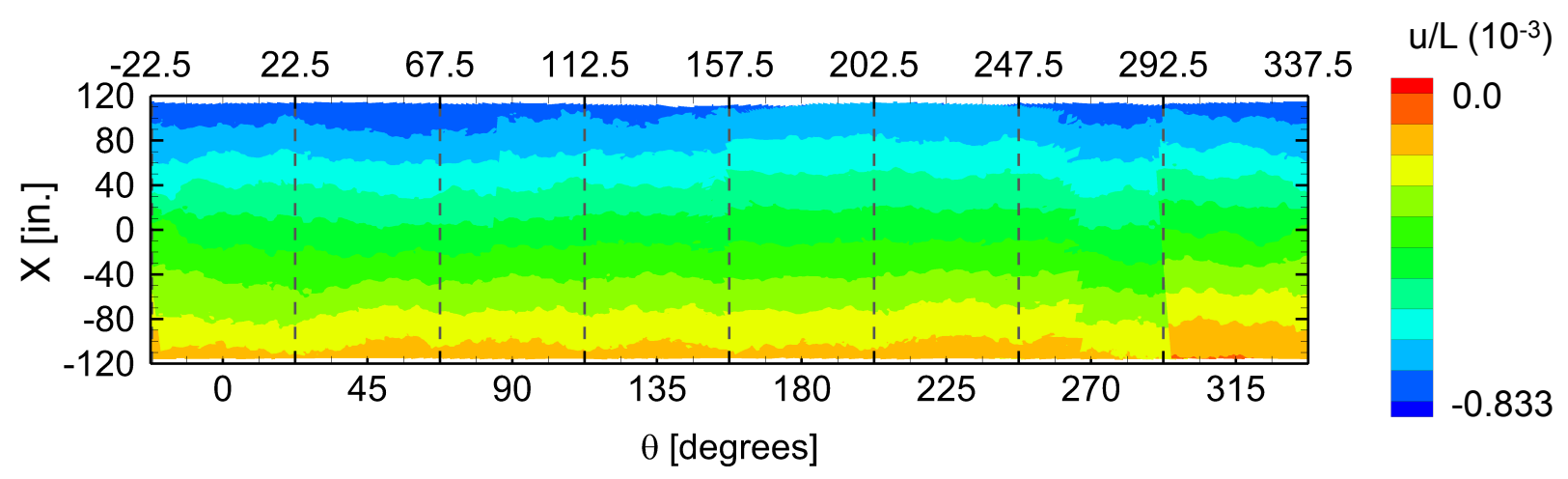

b) normalized axial displacement

Figure 29. Measured displacement contours incipient to weld land buckling in ETTA1 subjected to 0.6 psi internal pressure and a compression load of $97 \%$ Pcr, corresponding to loading point $d$ in Figure 25. (dashed lines indicate the location of longitudinal weld lands) 


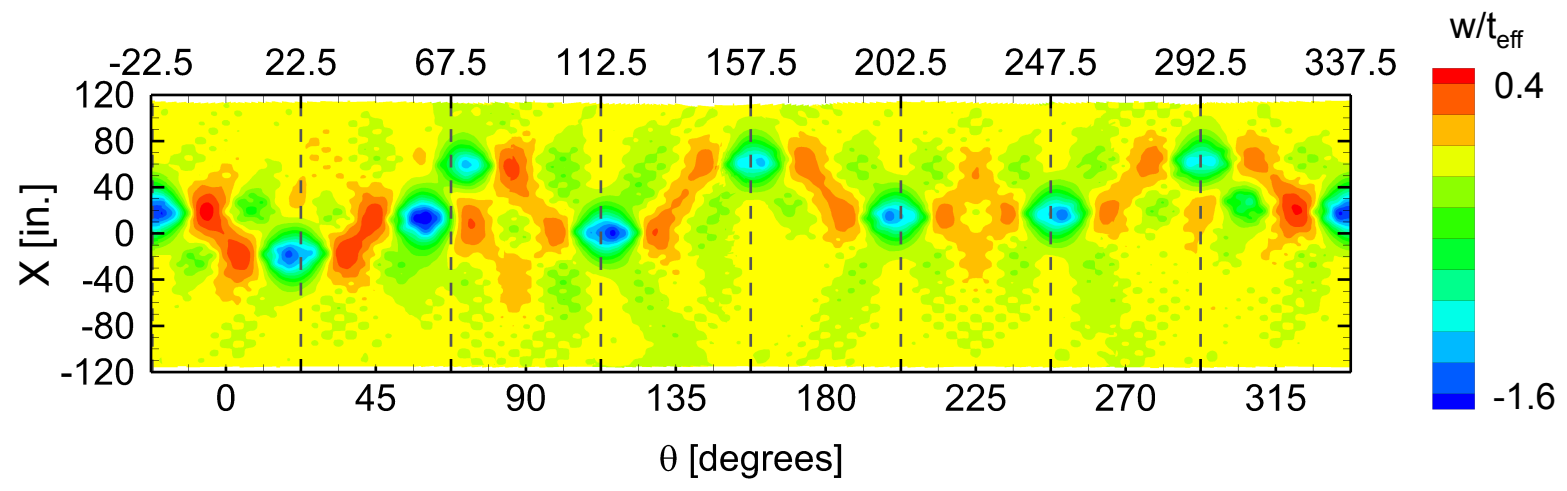

a) normalized radial displacement

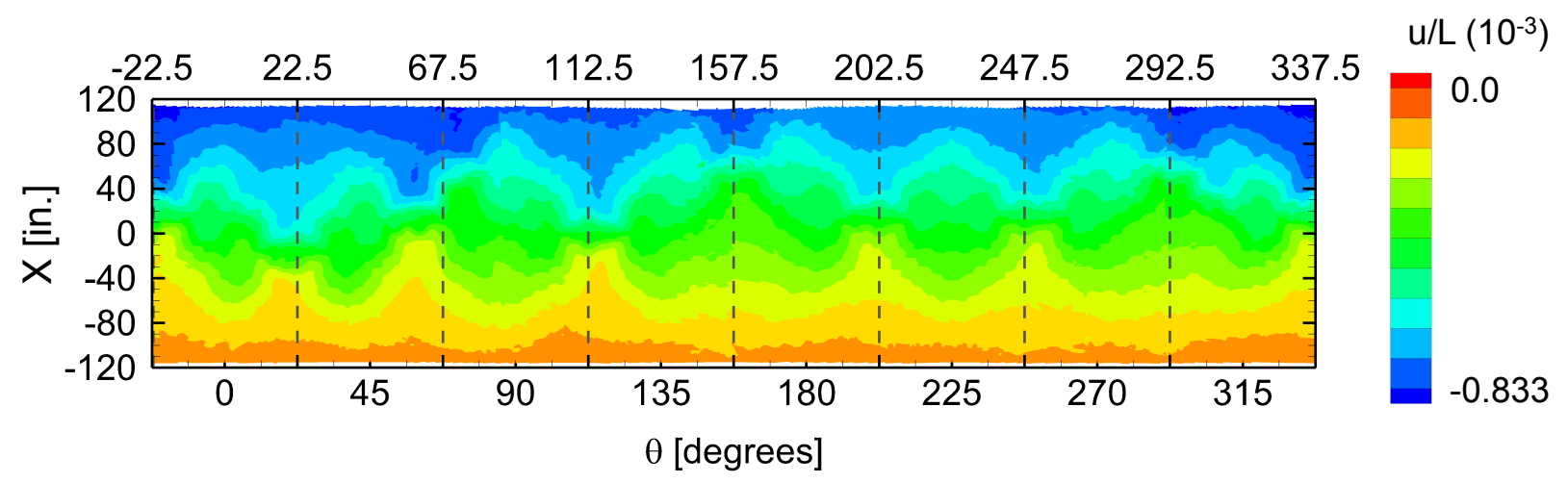

b) normalized axial displacement

Figure 30. Measured displacement contours after weld land buckling in ETTA1 subjected to 0.6 psi internal pressure and a compression load of $89 \%$ Pcr, corresponding to loading point e in Figure 25. (dashed lines indicate the location of longitudinal weld lands) 


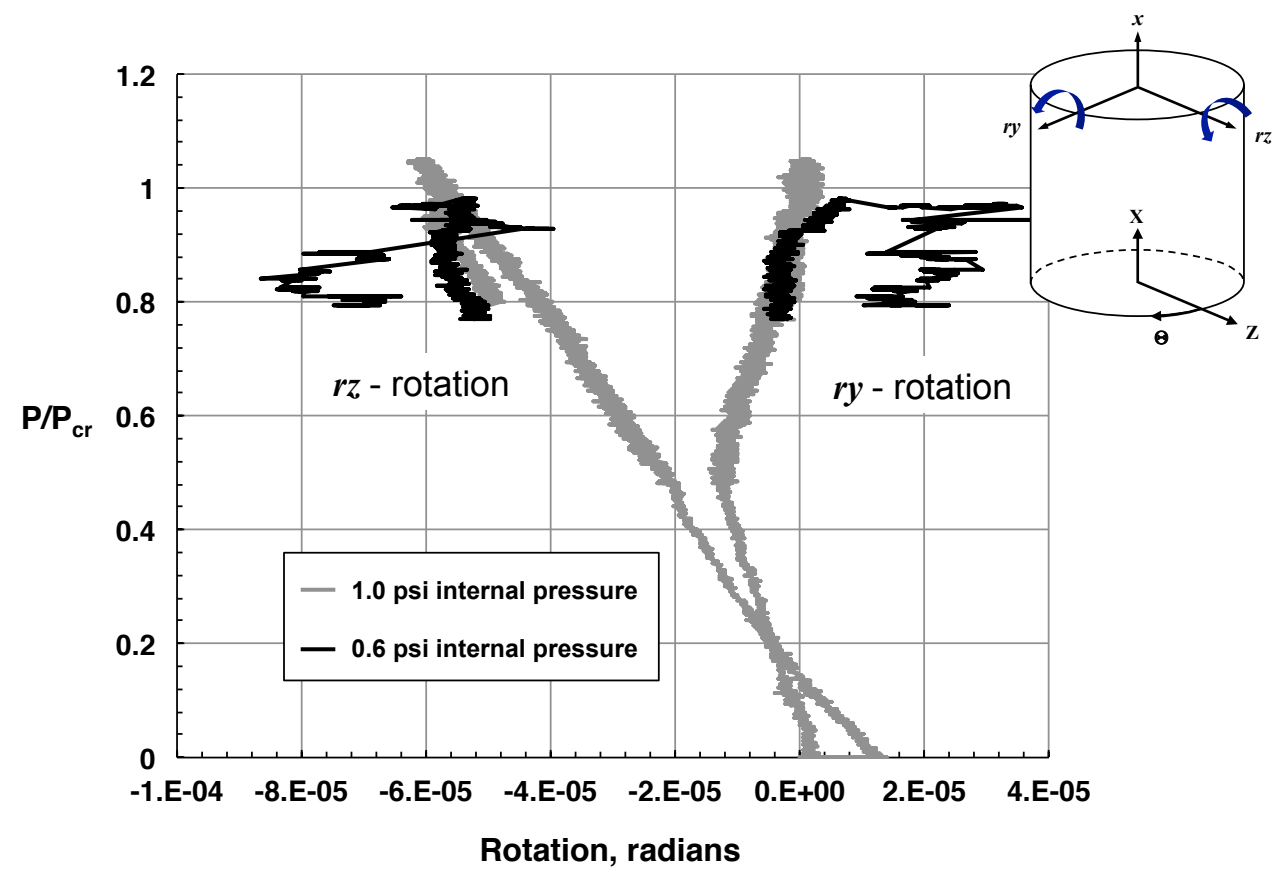

Figure 31. Load versus bending rotations for ETTA1 subjected to combined internal pressure and axial compression.

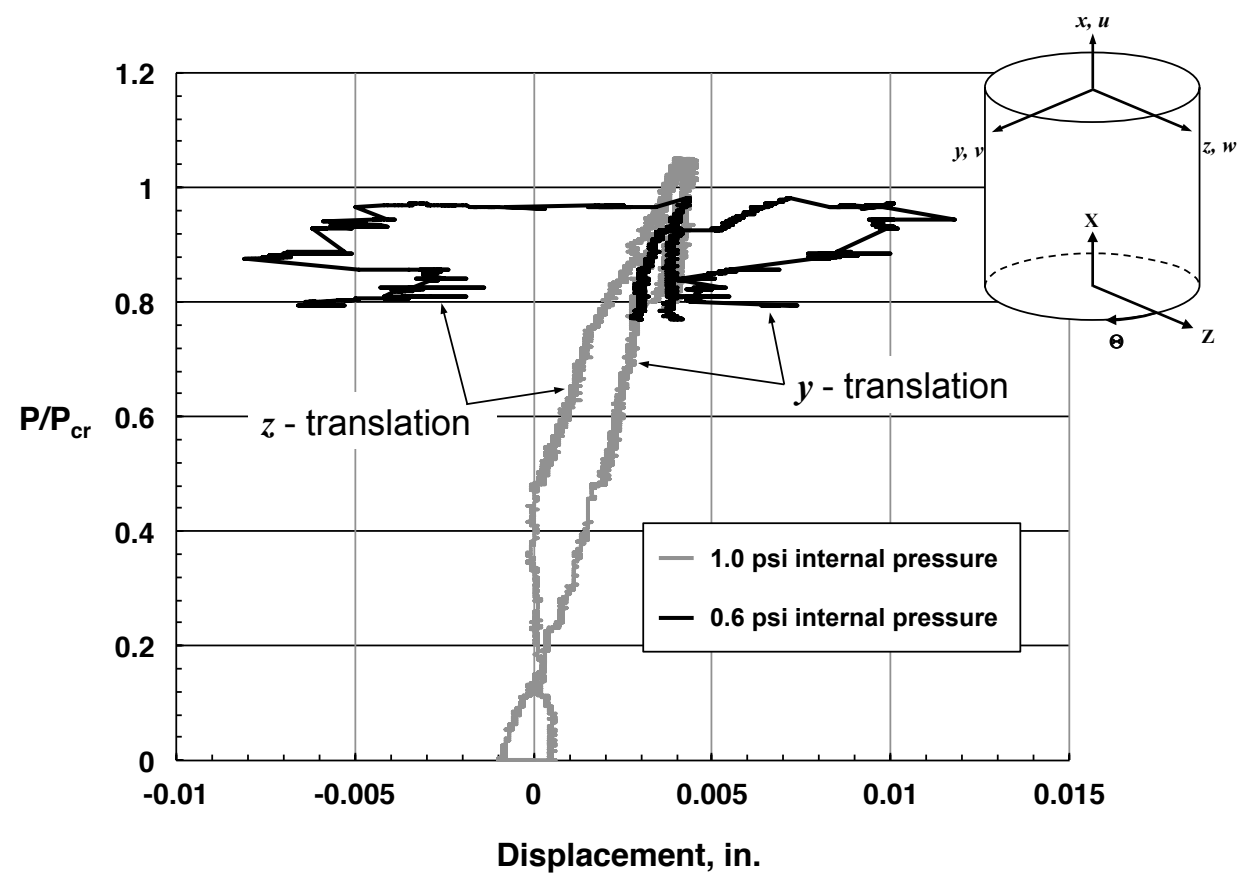

Figure 32. Load versus transverse displacements for ETTA1 subjected to combined internal pressure and axial compression. 


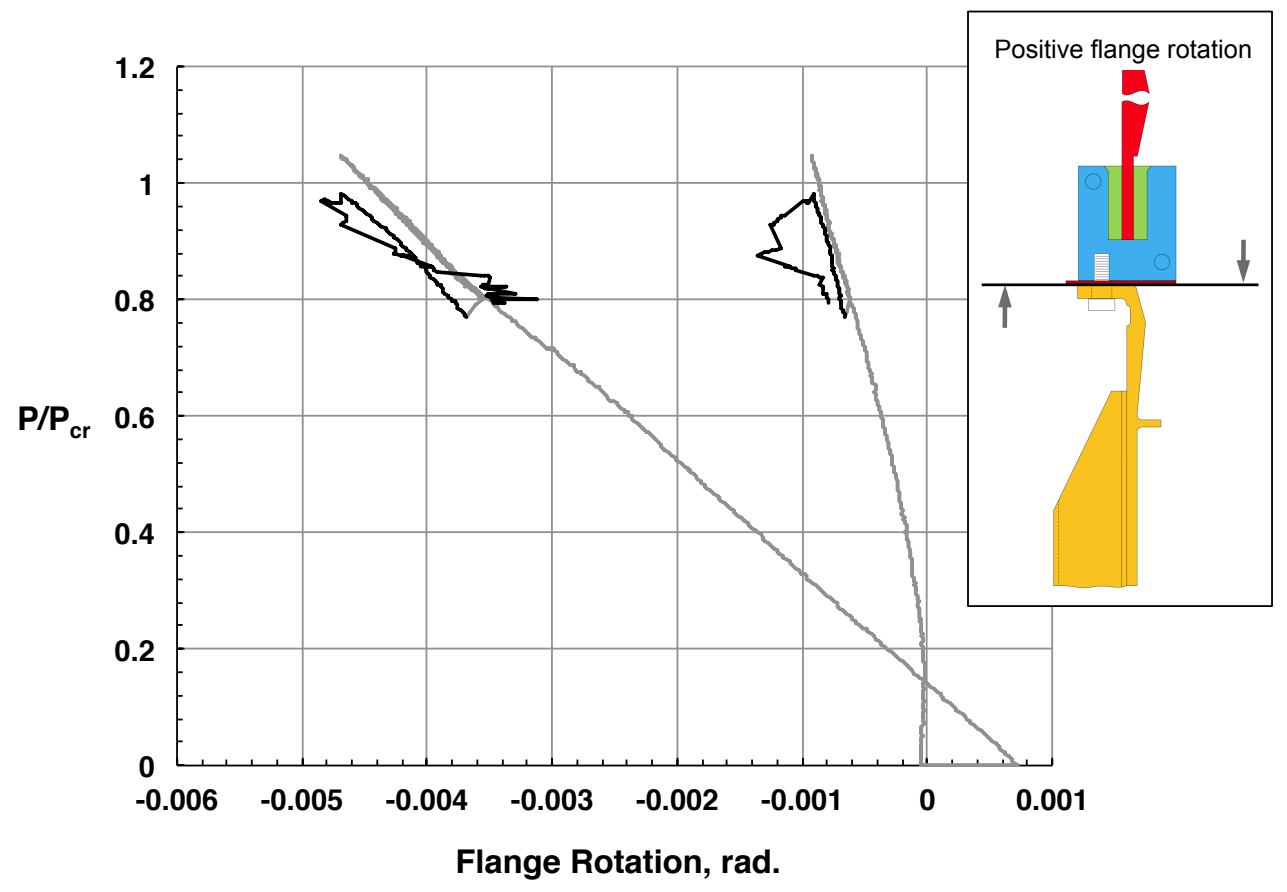

Figure 33. Load versus interface flange rotation for ETTA1 subjected to combined internal pressure and axial compression. 